\title{
Mapping the Spectral Soil Quality Index (SSQI) Using Airborne Imaging Spectroscopy
}

\section{Tarin Paz-Kagan ${ }^{1}$, Eli Zaady ${ }^{2}$, Christoph Salbach ${ }^{3}$, Andreas Schmidt ${ }^{3}$, Angela Lausch ${ }^{3}$, Steffen Zacharias ${ }^{4}$, Gila Notesco ${ }^{5}$, Eyal Ben-Dor ${ }^{5}$ and Arnon Karnieli ${ }^{1, *}$}

1 The Remote Sensing Laboratory, Blaustein Institutes for Desert Research, Ben-Gurion University of the Negev, Sede Boker Campus 84990, Israel; E-Mail: paztarin@gmail.com

2 Department of Natural Resources, Agricultural Research Organization, Gilat Research Center, 85280, Israel; E-Mail: zaadye@agri.gov.il

3 Department of Computational Landscape Ecology, UFZ Helmholtz Centre for Environmental Research, D-04318 Leipzig, Germany; E-Mails: christoph.salbach@ufz.de (C.S.); andreasdd.schmidt@ufz.de (A.S.); angela.lausch@ufz.de (A.L.)

4 Department for Monitoring and Exploration Technologies, UFZ Helmholtz Centre for Environmental Research, D-04318 Leipzig, Germany; E-Mail: steffen.zacharias@ufz.de

5 Department of Geography and Human Environment, Tel-Aviv University, Tel-Aviv 69989, Israel; E-Mails: gilano@post.tau.ac.il (G.N.); bendor@post.tau.ac.il (E.B.-D.)

* Author to whom correspondence should be addressed; E-Mail: karnieli@bgu.ac.il; Tel.: +972-8-659-6855; Fax: +972-8-659-6805.

Academic Editors: Nicolas Baghdadi and Prasad S. Thenkabail

Received: 31 August 2015 / Accepted: 9 November 2015 / Published: 23 November 2015

\begin{abstract}
Soil quality (SQ) assessment has numerous applications for managing sustainable soil function. Airborne imaging spectroscopy (IS) is an advanced tool for studying natural and artificial materials, in general, and soil properties, in particular. The primary goal of this research was to prove and demonstrate the ability of IS to evaluate soil properties and quality across anthropogenically induced land-use changes. This aim was fulfilled by developing and implementing a spectral soil quality index (SSQI) using IS obtained by a laboratory and field spectrometer (point scale) as well as by airborne hyperspectral imaging (local scale), in two experimental sites located in Israel and Germany. In this regard, 13 soil physical, biological, and chemical properties and their derived soil quality index (SQI) were measured. Several mathematical/statistical procedures, consisting of a series of operations, including a principal component analysis
\end{abstract}


(PCA), a partial least squares-regression (PLS-R), and a partial least squares-discriminate analysis (PLS-DA), were used. Correlations between the laboratory spectral values and the calculated SQI coefficient of determination $\left(\mathrm{R}^{2}\right)$ and ratio of performance to deviation (RPD) were $\mathrm{R}^{2}=0.84 ; \mathrm{RPD}=2.43$ and $\mathrm{R}^{2}=0.78$; $\mathrm{RPD}=2.10$ in the Israeli and the German study sites, respectively. The PLS-DA model that was used to develop the SSQI showed high classification accuracy in both sites (from laboratory, field, and imaging spectroscopy). The correlations between the SSQI and the SQI were $\mathrm{R}^{2}=0.71$ and $\mathrm{R}^{2}=0.7$, in the Israeli and the German study sites, respectively. It is concluded that soil quality can be effectively monitored using the spectral-spatial information provided by the IS technology. IS-based classification of soils can provide the basis for a spatially explicit and quantitative approach for monitoring SQ and function at a local scale.

Keywords: land-use change; imaging spectroscopy; reflectance spectroscopy; spectral soil quality index; soil quality index

\section{Introduction}

Soil quality (SQ) is considered to be a key element of sustainable soil function. SQ can be defined as the capacity of a soil-specific property to sustain the productivity of plants and animals, within the limits of the ecosystem (natural or managed), while maintaining or improving the quality of water and air, and supporting human health and habitation [1,2]. Soil formation or genesis is strongly dependent on the environmental conditions of both the atmosphere and the lithosphere and on long-term management [3]. SQ involves physical, biological, and chemical attributes that are merged together to indicate soil functioning [4,5]. Several studies have proposed conceptual frameworks for monitoring SQ [4,6]. These frameworks usually share common steps, including the selection of physical, biological, and chemical soil properties that are essential in terms of soil functioning [7]. Monitoring SQI at large spatial scales remains expensive, as well as time and labor consuming, when using the standard procedures due to the large number of soil analyses involved. In addition, SQ mapping requires the integrated consideration of key soil properties and their variations in space and time [8]. The developments of SQ maps with complete area coverage are needed for addressing climate change, land degradation, and hydrological processes in global and regional models. However, currently only a few spatially exhaustive datasets are available [9].

Remote sensing may offer possibilities for monitoring SQ at spatial scales relevant for modeling or management. Spectroscopy techniques that include the visible (VIS, 400-700 nm), near-infrared (NIR, 700-1100 nm), shortwave infrared (SWIR, 1100-2500 nm), and thermal infra-red (TIR, 8000-12000 nm) spectral ranges are well-known tools for monitoring and studying different aspects of soil surface properties and SQ with various levels of prediction accuracy [10-14]. Spectroscopy is a rapid, non-destructive, reproducible, and cost-effective analytical method that is used in food science, medical science, and all geoscientific disciplines, in general, and in soil science, in particular $[11,14,15]$. The spectral analysis procedure involves the preparation of soil samples, spectral acquisition, the preprocessing of spectral data, and the selection of an appropriate statistical model and each step can affect the accuracy of the model for 
each individual indicator [16]. Different pre-processing transformations (PPTs) have been applied to improve prediction ability [17,18], such as mean normalization, baseline offset, maximum normalization [17], first derivatives [19], the Savitzky-Golay smoothing algorithm [20], second derivatives [21], and generalized least squares weighting (GLSW) [22]. Such methods usually remove baseline effects and spectral noise, and reduce the impact of particle size [23]. Choosing the best performing PPTs depends on the dataset and requires testing to ascertain an effective model [18].

Reflectance spectroscopy is used in chemometrics to construct spectral groups' classification and regression models to predict many soil attributes. While regression methods are used to model the spectral signature of a target based on specific physical, biological, or chemical soil properties, classification is used to group the spectral signatures of soil into categories [24-27]. The statistical models have included parametrical methods such as partial least squares-regression (PLS-R), which is perhaps the most commonly used regression method technique (e.g., [12,14,28]). An example of a parametric classification method is the partial least squares-discriminant analysis (PLS-DA), which is a method for the supervised classification of spectral data. In the current study, we developed a conceptual framework for SQ maps based on the parametric methods (PLS-R and DA).

Recent studies have presented the ability of reflectance spectroscopy to monitor SQ. Cohen et al. [29] successfully predicted several soil properties using VIS-NIR spectroscopy as indicators of wetland SQ. They concluded that spectroscopy offers both cost and statistical power advantages for the integrative assessment of SQ in wetlands. Velasques et al. [27] successfully classified different tropical agro-ecosystem soils by using spectroscopy. Idowu et al. [30] evaluated SQ by 39 physical, biological, and chemical soil properties, using a combination of field, laboratory, and spectroscopic methods in New York State, USA, and stated that in order to advance the application of VIS-NIR spectroscopy, research should begin by establishing the spectral assessment of SQ across all soil parameters. Kinoshita et al. [23] discussed the potential of soil spectroscopy for predicting multiple soil properties simultaneously by multidimensional SQI in a western Kenyan chronosequence. They found that laboratory analyses for several physical, biological, and chemical soil properties could be replaced with a spectral analysis for SQ scores. The use of reflectance spectroscopy for the multidimensional assessment of the impact of land-use change on SQ for three land uses (afforestation, traditional grazing, and agro-pastoral) was presented by Paz-Kagan et al. [31]. Their study evaluated the spectral predictability of $14 \mathrm{SQ}$ indicators along with an integrated spectral soil quality index (SSQI). Askari et al [10] used spectroscopic and chemometric analyses to classify soil structural quality using 40 sites in Ireland under arable and grassland management systems. They found that spectroscopy is a suitable technique for the quantitative assessment of SQ. The above recent studies pave the way for developing an applied tool that can be used for land-use management in the context of soil security, soil health, and soil protection.

Although remote sensing and soil spectroscopy have been recognized as potentially effective techniques for monitoring SQ, they have been only rarely used with imaging spectroscopy (IS) since the first paper of Ben-Dor et al. [32]. The ability to map soil with an airborne IS sensor has progressed with the development of relatively cheap and better signal-to-noise sensors that are easy to operate and available to all. IS presents a new spatial dimension for spectral information and provides a new capability for many existing soil (point) spectroscopy applications. However, moving from point measurements to the IS domain not only means a transition from micro- to macroscales, but also 
involves a whole new set of challenges [3,33]. Among these are the low signal-to-noise ratio of most of the IS sensors (relative to the point spectrometer), large datasets, the effects of the bidirectional reflectance distribution function (BRDF), the spectral instability effect [34], the spectral mixing problem, optical shifts from one pixel to another, atmospheric interference, and crust and vegetation cover [3]. Because most of the applications for SQ have been developed for point spectrometry, their immediate adaptation for the IS domain requires proper attention and adequate solutions to minimize the abovementioned problems [3]. Although the potential of IS as a technique for the rapid and simultaneous prediction of soil properties is known, the challenge is to adapt the application of IS into a diagnostic screening tool that can assist in developing reliable SQ surface maps for land management at large spatial scales [35]. In addition, there is a need to connect point soil spectroscopy and IS in order to relate them to functional soil properties and quality. Several studies have presented the ability to upscale laboratory models to airborne IS. These studies include, for example: soil degradation (salinity, erosion, and deposition) maps, soil mapping and classification, soil genesis and formation, soil contamination, soil water content, and more [3,33,36-39]. However, most of these studies used either single or several soil properties and not an integrated approach such as the SQI.

The primary aim of this research is to prove and demonstrate the ability of IS means to evaluate soil properties and quality across anthropogenically induced land-use changes. This objective was fulfilled by implementing the SSQI with IS data obtained by a laboratory and field point spectrometer, as well as by an airborne imaging spectrometer, in two experimental sites located in Israel and Germany. The proposed SSQI was compared with a commonly used soil quality index (SQI) determined by traditional physical, biological, and chemical soil analyses and accomplished by a series of mathematical/statistical procedures.

\section{Methods}

\subsection{Study Sites}

Two study areas, one located in Israel (a long-term ecological research (LTER) site) and one in Germany (an intensive research site of the TERENO Observatory "Harz/Central German Lowland, Zacharias et al. [40]), were selected for examining the abovementioned aims. The sites differ in their environmental conditions, soil properties, and management regimes and, therefore, well represent the diverse areas in which the suggested SSQI can be tested. In each research site, three management regimes were tested.

\subsubsection{Agricultural Research Site, Northwestern Negev Desert, Israel}

The Migda experimental farm belongs to a series of LTER sites in the northern Negev Desert, Israel (Figure 1A) $\left(34^{\circ} 25^{\prime} \mathrm{E}, 31^{\circ} 22^{\prime} \mathrm{N}\right)$ [41]. The total area of the Migda experimental farm is about 162 ha, and the elevation is 100-120 m a.m.s.l. The area is characterized by a mean annual rainfall of $230 \mathrm{~mm}$ that is concentrated during the rainy season between November and April. Average daily temperature ranges from $10{ }^{\circ} \mathrm{C}$ in the winter to $30{ }^{\circ} \mathrm{C}$ in the summer. The bedrock lithology is an Eocenian chalk. The soils are sandy-loamy loess, defined by the local Israeli definition system, and calcic haploxeralf according to the USDA's definition, and the texture composition is $20 \%$ clay, $38 \%$ silt, and $42 \%$ sand. 
The farm was established in 1960 by the Agricultural Research Organization (ARO), supporting extensive agriculture that includes grazing under different grazing regimes. The main crop is spring wheat [42], growing annually during the rainy season from November to April. The farm has been grazed every year by a flock of about 800 Awassi sheep and 600 goats, starting in late February, when the field is fully covered, continuing until May (green pasture), and again from June to December (dry pasture). The grazing in the farm is managed by controlling the intensity, stocking density, flock size, and timing of herd introduction into the field. Three experimental systems were examined: (1) an abandoned agricultural field with natural vegetation in an area of 5 ha of mainly annual plants. In this field, no cultivation, irrigation, fertilization, or grazing has been performed for the last 40 years; (2) an abandoned field in an area of 9.6 ha, mainly with annual plants, with grazing, but with no cultivation, fertilization, or irrigation; and (3) a monocultural agro-pastoral field of wheat in an area of 9.5 ha, with moderate grazing and cultivation but with no fertilization or irrigation.
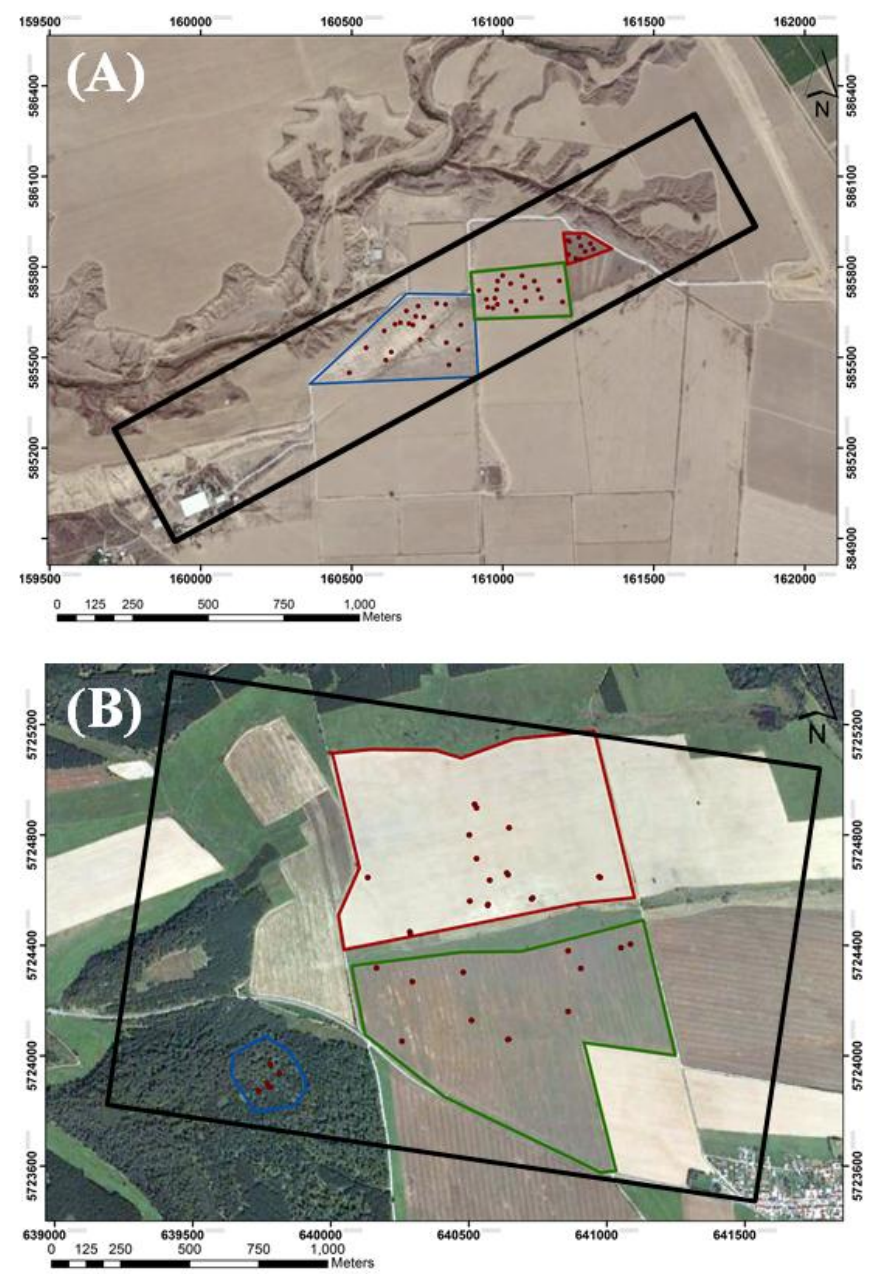

\section{Migda site Israel}

Abandoned field with no grazing

Agro-pastoral grazing

Abandoned field with grazing
Schäfertal site, Germany

Fertilized agricultural field

Unfertilized agricultural field

Forest

- Sampling points

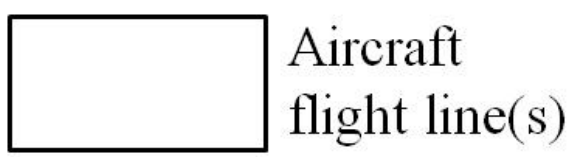

Figure 1. Aerial photograph of the study areas with their land-use categories: (A) Migda site, Israel; and (B) Schäfertal site, Germany.

\subsubsection{Harz/Central German Lowland Agricultural Site}

The Schäfertal research catchment is located in the lower eastern Harz Mountains, Germany (Figure 1B) $\left(11^{\circ} 02^{\prime} \mathrm{E}, 51^{\circ} 39^{\prime} \mathrm{N}\right)$. The study area is about 144 ha, and the elevation is $393 \mathrm{~m}$ a.m.s.l. The climate regime is moderate continental that is influenced by its leeward position. The average annual 
rainfall is $636 \mathrm{~mm}$ with a mean annual temperature of $6.8{ }^{\circ} \mathrm{C}$, ranging from $1.8{ }^{\circ} \mathrm{C}$ in January to $15.5{ }^{\circ} \mathrm{C}$ in July. Luvisols and Cambisols soil groups, according to the FAO's classification [43], cover the slopes and are intensively used for agriculture [44]. Lower relief positions near the channel are characterized by the Gleysols soil group that is mainly used for pasture. All of the soils have a loamy character with a texture composition of about $21 \%$ clay, $53 \%$ silt, and $24 \%$ sand [45]. The entire catchment is divided into five fields, managed by one agricultural cooperative society that provides information such as fertilization and crop yield. Ploughing and harrowing is conducted in autumn. Major crops in the catchment are winter cereal and winter rapeseed, whereas 3\% of the area is forested. Three experimental systems were examined: (1) a fertilized agricultural field that was fertilized several days before the flight campaign with urea and ammonium nitrate. In addition, the field was harvested and sown with winter rapeseed; (2) an unfertilized agricultural field that was harvested and sown with winter rapeseed. The latest fertilizer application (nitrogen and sulphur) on the field was in April 2013; and (3) a forest area.

\subsection{Data Collection and Analysis}

The current study involves several spectral datasets as illustrated in Figure 2 (laboratory, field, and airborne). Two flight campaigns were performed using Aisa (AisaDUAL and AisaFENIX) hyperspectral sensors onboard light aircrafts. One flight campaign took place on 6 September 2013 over the German site and the other on 19 September 2014 over the Israeli site. Both campaigns were carried out at the end of the dry season to minimize the effects of soil water content, annual vegetation, and cloud effects. During the campaigns, the skies were clear and the agricultural fields were exposed with bare soil. The flight campaigns were accompanied by field and laboratory spectral measurements, and by soil sampling in which the samples were transferred to laboratories for physical, biological, and chemical analyses. The soil sampling design in the two sites covered the different experimental systems, and the sampling points were randomly selected in each system. The spectral and soil data analyses were jointly subjected to a chain of mathematical/statistical procedures, namely PCA, PLS-R, and PLS-DA.

\subsubsection{Field and Laboratory Spectral Measurements}

In each of the study sites, the soil spectra were acquired under field conditions (undisturbed samples) and under laboratory conditions with the portable analytical spectral device (ASD) Field Spec ${ }^{\circledR}$ Pro spectrometer. Prior to the laboratory spectral measurements, the soil samples were air dried, ground, and passed through a 2-mm sieve. The ASD covers a spectral range of 350-2500 nm and has a $25^{\circ}$ field of view. The instrument was repeatedly calibrated to spectral reflectance using a standard white reference panel (Spectralon Labsphere Inc., North Sutton, NH, USA). A total of 50 soil samples were collected in the Migda site (20 in the monocultural agro-pastoral field; 20 in the abandoned field with grazing; and 10 in the abandoned agricultural field). A total of 25 soil samples were collected in the Schäfertal site (10 in the fertilized agricultural field; 10 in the unfertilized agricultural field; and 5 in the forest). Reflectance data in the laboratory were measured under stable illumination from two directions while the spectrometer's fiber aperture was fixed at a constant height of $18.5 \mathrm{~cm}$ above the sample platform; thus, the diameter of the sample was $8 \mathrm{~cm}$. The bidirectional 
illumination reduced the effects of micro-topography shadowing. In addition, each sample was measured four times, while rotating the sample $90^{\circ}$ between each reading. These four readings were later averaged to a final value representing the spectral resolution of $1 \mathrm{~nm}$. The spectral resolution of the ASD varies from $3 \mathrm{~nm}$ in the VIS-NIR range to $8-10 \mathrm{~nm}$ in the SWIR range. We resampled the ASD's spectral band to $1 \mathrm{~nm}$ uniformly along the entire spectral region. Finally, the data were spectrally resampled to the spectral configuration of the airborne sensors (see next section). The field spectral measurement was vertical in relation to the soil surface using the same ASD spectrometer in the Israeli site that was used in the laboratory, however with unexposed fiber (i.e., exposed to interior fixed lighting and not to the sun). To reduce spectral noise, four spectral readings for each soil sample were measured and averaged to a final value representing the field sample. In the Schäfertal site, undisturbed soil samples were measured in the same laboratory conditions as mentioned above. The soil samples in Schafertal site were measured in the same laboratory conditions since the weather did not allow ASD field measurements.

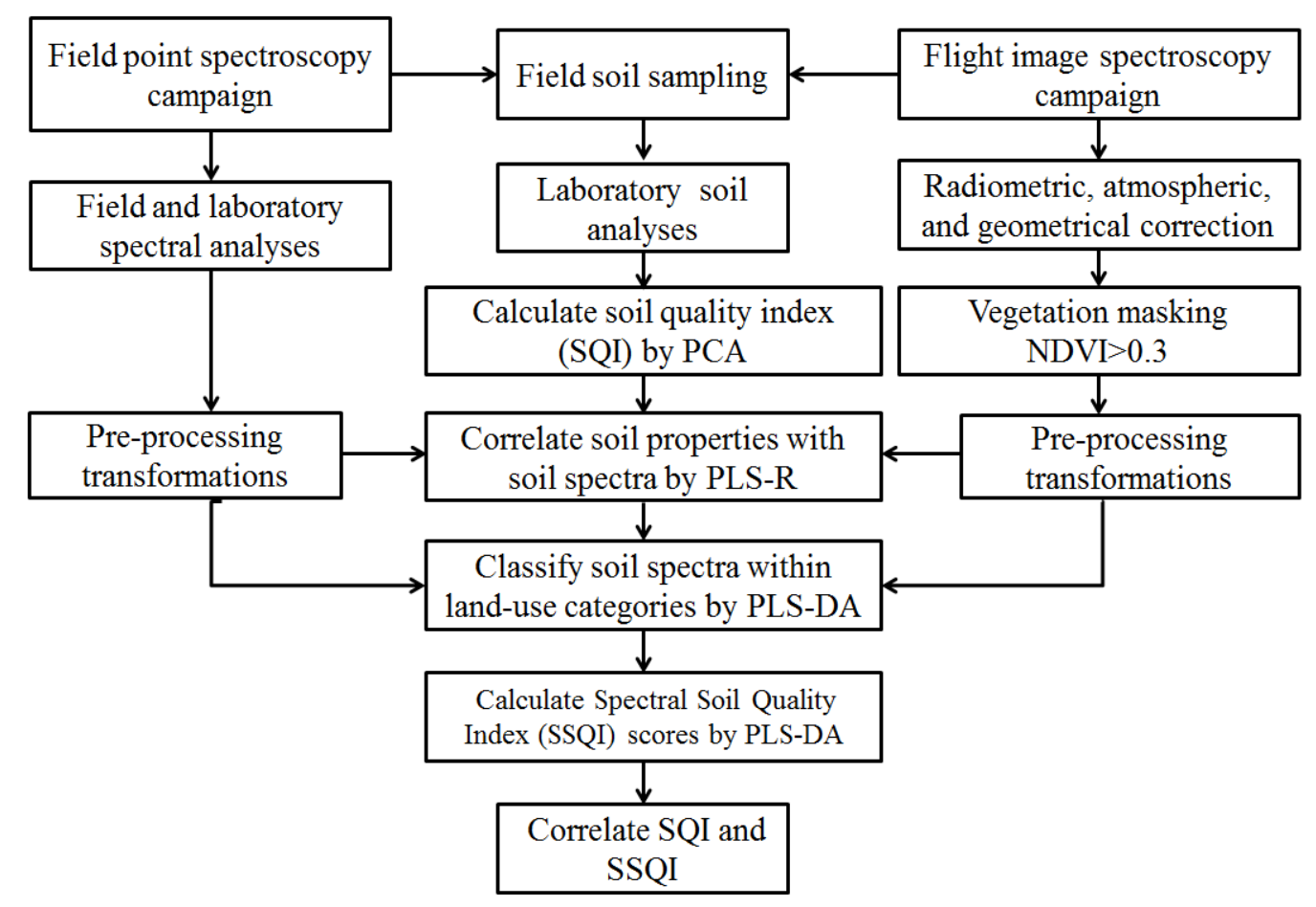

Figure 2. Study flowchart for developing the soil quality index (SQI) and the spectral soil quality index (SSQI) by applying laboratory, point, and image spectroscopy data along with complementary soil measurements and analyses.

PPTs of the spectral data included three types: (1) A second-order transformation of the polynomial Savitzky-Golay smoothing $[20,46]$ was performed to minimize variance between samples caused by grinding and the optical setup. This transformation was found to be an optimal spectral pretreatment in similar studies $[19,47,48]$. (2) An autoscale transformation was performed, which is an exceptionally common pre-processing method that uses mean-centering followed by dividing each variable by the standard deviation (SD) of the variable. This approach is a valid method with which to correct differing variable scaling and units if the predominant source of variance in each variable is signal rather than noise. Under these conditions, each variable is scaled such that its useful signal has an 
equal footing with the other variables' signals [49]. Finally, (3) a GLSW transformation was performed to produce a filter matrix based on the differences between pairs or groups of samples that should otherwise be similar [50]. The single adjustable parameter, $\alpha$, that defines how strongly GLSW downweights interferences was set to 0.02 . Adjusting $\alpha$ towards larger values (typically above 0.02 ) decreases the effect of the filter, while smaller $\alpha$ values (typically 0.001 and below) apply more filtering. The prediction process included randomly selecting the spectral sample dataset (25\%) to calibrate the model for the prediction of known samples.

\subsubsection{Airborne Imaging Spectroscopy}

Flight campaigns were performed over the two study systems using two different SPECIM's AISA hyperspectral airborne sensors, AisaFENIX (in Israel) and AisaDUAL (in Germany). AisaFENIX is a hyperspectral sensor with a single optic that provides a continuous image, covering the VIS-NIR-SWIR spectral region (380-2500 nm) with 448 spectral bands and a FWHM of 3.5-5.5 nm. The sensor was mounted onboard a light aircraft that was flown at an altitude of $762 \mathrm{~m}$, resulting in a spatial resolution of $1 \mathrm{~m}$, under good weather conditions, over the study area at the Migda site. Another data cube was acquired over a nearby ground calibration site, located on the flight trajectory, and included net targets usually used for a supervised vicarious calibration (SVC) procedure [51]. The AisaDUAL sensor is a hyperspectral sensor with a computable pushbroom airborne imaging spectrometer, covering the 420-2450 nm spectral range with 367 spectral bands. A bandwidth of $4.5 \mathrm{~nm}$ exists in the VIS and NIR regions, and of $6.3 \mathrm{~nm}$ in the SWIR region. This sensor combines the AisaEAGLE (400-970 nm) and the AisaHAWK (970-2500 nm) sensors with different optics, boresighted to each other, resulting in a 2-3 pixel offset. The AisaDUAL sensor was mounted onboard a light aircraft that was flown over the study area at the Schäfertal site, at an altitude of $768 \mathrm{~m}$, resulting in a spatial resolution of $1 \mathrm{~m}$, under good weather conditions. An inertial measurement unit (IMU) enabled global positioning system (GPS) device was used to record the geo-positional data of the aircrafts for geometric rectification in the Migda and Schäfertal sites.

AisaFENIX raw data were processed using the CALIGEO software (Spectral Imaging Ltd), resulting in georectified radiance images. The Migda site radiance image was atmospherically corrected using the ACORN-6 software (ImSpec LLC, Advanced Imaging and Spectroscopy) with a gain factor derived from the SVC site image processing. The resultant reflectance image was used henceforth. The AisaDUAL raw data were radiometrically corrected with the CALIGEO software by Spectral Imaging Ltd. Afterwards, the reduction of miscalibration effects (ROME) destriping algorithm was applied to reduce sensor miscalibration effects [52]. The geometric correction of the AisaDUAL data was performed with the PARGE software (ReSe Applications). The BREFCOR method was used for a surface-cover-dependent correction of bidirectional effects [53]. BREFCOR was implemented in the ATCOR-4 package version 6.3 (ReSe Applications) and was also used to calculate the reflectance values for the image. The positional accuracy was improved with geo-referencing and high resolution orthophotos. At the end, six flight lines were stitched into one mosaic.

To minimize the vegetation signal in the image, the normalized difference vegetation index (NDVI; Tucker [54]) was calculated in the images. A threshold of NDVI $\leq 0.3$ was selected to represent bare soil [55]. The areas with an NDVI that was higher than 0.3 were masked out from further analysis. Due to vegetation cover in the abandoned agricultural field with natural vegetation in Migda, and in the 
forest in the Schäfertal site, the analyses of the images were further conducted only in the fields with bare soil. Following the image pre-processing, the spectra of the selected soil samples were extracted according to the GPS points that were sampled in the field. The extraction of the pixels from the images was calculated by averaging the pixels in a 1-m area around the selected point. In addition, elimination of the spectral channels affected by atmospheric water absorption in the images was done (excluded were the 1340-1448 and 1792-2000 spectral bands).

Figure 3 presents the average spectral signature of the laboratory, field, and airborne data, in the different experimental systems in the two study sites. Spectral differences exist between the laboratory, field, and airborne datasets. The spectral soil signatures are affected by soil aggregation, particle size distribution, water content, and the presence of additional elements, such as vegetation litter, rock particles, and mineral deposits. Therefore, laboratory standardization of the sample preparation and measurement protocols was carried out to minimize these BRDF effects. The spectral soil signatures from the field data did not include preliminary preparation of the soil, and these signatures are affected by the soil structures and water content. The soil signature of the image is affected by the soil structure and other effects such as atmospheric interference, the BRDF effect, and more. In addition to these effects, there are a different number of spectral bands in each sensor.
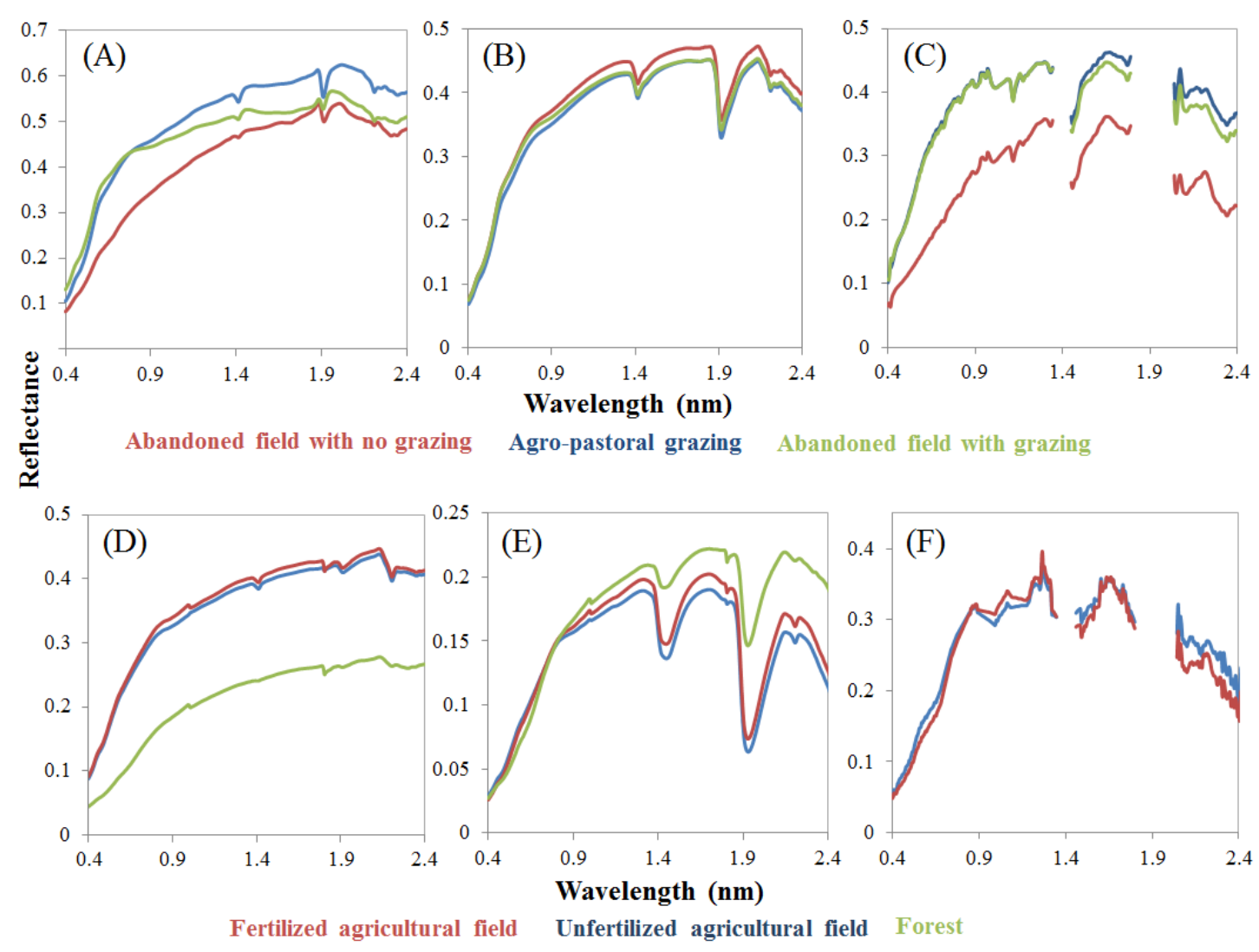

Figure 3. The average spectral signatures of the two study sites: Migda, Israel (A, B, C) and Schäfertal, Germany (D, E, F). The spectral dataset included: (A and D) laboratory spectral signatures; ( $\mathrm{B}$ and $\mathrm{E}$ ) field spectral signatures; and ( $\mathrm{C}$ and $\mathrm{F}$ ) airborne imaging spectral signatures. The land-use classes are characterized by the different colors. 


\subsubsection{Soil Sampling and Laboratory Analysis}

Soil samples were collected during the flight campaigns, at a depth of $0-0.15 \mathrm{~m}$. The sampling was conducted following a stratified random survey methodology. As mentioned before, in total, 50 soil samples were collected in the Migda site and 25 in the Schäfertal site. The soil sampling was accomplished by accurate GPS and surface hardness (SH) measurements. Hydraulic conductivity (HC) measurements were performed only in Israel under dry soil conditions in the field. All soil samples were transferred to the laboratory and were stored unopened at room temperature until analysis.

The Cornell Soil Health Test (CSHT) protocols were adopted for analyzing 13 physical, biological, and chemical soil properties [5,30,56]. The physical properties included soil texture (fractions of clay, silt, and sand), available water capacity (AWC), surface hardness ( $\mathrm{SH}$ ), and hydraulic conductivity measured under saturated conditions (HC). The biological properties included potential active carbon (PAC) and soil organic matter (SOM). The chemical properties included $\mathrm{pH}$, electrical conductivity (EC), extractable ammonium $\left(\mathrm{NH}_{4}{ }^{+}\right)$, extractable nitrate $\left(\mathrm{NO}_{3}{ }^{-}\right)$, extractable phosphorus (P), and extractable potassium (K). All laboratory measurements were performed with CSHT's standards [5]; however, minor modifications were introduced due to the specific management practices, climatic regions, and available tools. These included: (1) available water capacity (AWC) that was measured by the soil moisture as water retention characteristics [57]; (2) $\mathrm{NH}_{4}{ }^{+}$and $\mathrm{NO}_{3}{ }^{-}$that were measured by potassium chloride extracts [58]; and finally (3) the hydraulic conductivity property that was measured by a mini-disk infiltrometer in the field [59]. Although the soil texture--the composition of the three fractions of clay, silt, and sand--is a main factor for the SQ, it is barely affected by soil management and, therefore, is not treated as a quality variable in itself. Thus, soil texture is not included in the SQI.

\subsubsection{Soil Quality Index (SQI)}

Evaluation of the SQ was carried out using the general approach of the SQI, involving scoring functions for each of the abovementioned soil properties [60]. The scoring functions were defined in a simple nonlinear polynomial framework. Each soil property was transformed through a scoring algorithm into a unitless score (0 to 1 ) representing the associated level of function in that system so that the scores could be combined to form a single value [1,61]. The distribution of each of the soil variables was assessed based on a Gaussian function $[62,63]$. The interpretation of the scoring function was integrated into an index calculated by a PCA $[64,65]$. The index values ranged from 0 to 1 ; low values indicated poor soils, while high values indicated healthy soils [5].

The soil property values were recorded by the different algorithms (scoring functions) to transform them into unitless scores $(\mathrm{S} i$ ) for each soil property $(i)$, using the following equations $[23,63,64]$ :

$$
\begin{gathered}
\mathrm{S} i_{m i b}=\left(1+\mathrm{e}^{-(\mathrm{b}(\mathrm{x}-\mathrm{a}))}\right)^{-1} \\
\mathrm{~S} i_{i i b}=\left(1+\mathrm{e}^{(\mathrm{b}(\mathrm{x}-\mathrm{a}))}\right)^{-1} \\
\mathrm{~S} i_{o p}=1 \times \mathrm{e}^{\left(-\frac{(x-a)^{2}}{b}\right)}
\end{gathered}
$$

where $x$ is the normally distributed soil property value, $a$ is the baseline value of the soil property where the score equals 0.5 (inflection point) or the population mean, and $b$ is the slope tangent of the baseline curve or $2 \sigma^{-2}$ of the population. The general shape of each function is characterized by the 
nature of the soil property with respect to SQ that can be either (1) more is better (mib): an upper asymptotic sigmoid curve (negative slope) that characterizes $\mathrm{AWC}, \mathrm{SOM}, \mathrm{PAC}, \mathrm{NH}_{4}{ }^{+}, \mathrm{NO}_{3}{ }^{-}$, and $\mathrm{K}$;

(2) less is better (lib): a lower asymptote (positive slope) that characterizes $\mathrm{SH}$; or (3) optimum function $(o p)$ : a Gaussian function that characterizes $\mathrm{pH}, \mathrm{EC}, \mathrm{P}$, and $\mathrm{HC}$. The specific shapes and the values are determined according to prior knowledge as presented in the literature and by experts (e.g., [63,64]). All the soil measurement scores were integrated from the previous stage into a single additive index value termed an SQI (Equation (2)). This value is considered to be an overall assessment of SQ, reflecting management practice effects on soil function. To evaluate the index, we used the PCA procedure for pinpointing combinations of variables that describe major trends in the data:

$$
\mathrm{SQI}=\sum_{i=1}^{n} P W i \times S i
$$

where $P W_{i}$ is the PCA weighting factor. Standardized PCAs of all (untransformed) data that differed significantly between treatments in the different land uses were performed using the MATLAB package (MathWorks, Natick, Massachusetts, USA) with a PLS toolbox (Eigenvector, Wenatchee, Washington, USA). The equations were normalized to obtain a maximum SQI with a score of one. Principal components (PCs) with eigenvalues higher than one that explained at least $5 \%$ of the variations of the data were examined [4,63]. Under a particular PC, only the variables with a high factor loading were retained for SQ indications. High factor loading was defined as having an absolute value within $10 \%$ of the highest factor loading. When more than one variable was retained under a single PC, a multivariate correlation was employed to determine whether the variables could be considered redundant and, therefore, eliminated from the SQI. If the highly loaded factors were not correlated, then each was considered important and, thus, retained in the SQI. Among well-correlated variables, the variable with the highest factor loading (absolute value) was chosen for the SQI. Each PC explained a certain amount of variation (percent) in the total dataset, and this percentage provided the weight for the variables chosen under a given PC. In order to evaluate the relative importance of each waveband in each of the PLS-R models, the variable importance in projection (VIP) was computed to reveal the score for each wavelength [66].

\subsubsection{Correlation between Soil and Spectroscopy Analyses}

A PLS-R cross-validation was used to correlate the spectral data with all laboratory soil measurements and the integrated SQI. A PLS-R is a predictive module technique to predict soil attributes, even when there are many predictor variables that are highly collinear [14,67]. The technique is closely related to a principal components regression (PCR). However, unlike the PCR, the PLS-R algorithm selects orthogonal factors that maximize the covariance between predictor (X spectra) and response variables (Y soil laboratory data or scores). The PLS-R analysis was applied with the full cross-validation of the Venetian Blinds method [65] with a 70 to 30 split ratio between the calibration and the validation sets. The ratio between the calibration and validation datasets was 35 to 17 and 15 to 8, in the Migda site and the Schäfertal sites, respectively. The PPTs that were used include the Savitzky-Golay algorithm, auto scaling, and GLSW. The prediction was evaluated by the root mean square error of calibration and cross-validation (RMSEC and RMSECV), as well as by the coefficient of determination $\left(\mathrm{R}^{2}\right)$ values of the relation between the predicted and observed soil 
properties, and by the ratio of performance to deviation (RPD), calculated as RPD $=$ SD/RMSECV. A particular focus was placed on RPD and $\mathrm{R}^{2}$ because the differences in units and the SDs of the indicators made the interpretation of RMSE difficult. Using the interpretation criteria of [23], the prediction models were categorized as "excellent" with $\mathrm{RPD} \geq 2.5$ and $\mathrm{R}^{2} \geq 0.80$, "good" with RPD between $2-2.5$ and $\mathrm{R}^{2} \geq 0.70$, "moderate" with RPD between $1.5-2$ and $\mathrm{R}^{2} \geq 0.60$, and "poor" with $\mathrm{RPD} \leq 1.5$ and $\mathrm{R}^{2} \leq 0.60$.

\subsubsection{Spectral Soil Quality Index (SSQI)}

A PLS-DA was performed to quantify the changes in SQ in the different land uses in the two study systems. The PLS-DA is a variant of PLS modeling and aims to find the variables and directions in multivariate space that determine the known classes in a calibration set. The predictor (X spectra) and the response variables are the classification category variables (Y values) [68]. The PLS-DA is a linear regression method whereby the multivariate variables, corresponding to the observations (spectral descriptors), are related to the class membership for each sample (land-use category or treatment). This method provides an understandable graphical means of identifying the spectral regions of difference between the classes and also allows for a statistical evaluation as to whether the differences between classes are significant. It takes into account the spectra and the soil attributes as a whole and classifies the spectral data. The strength of the PLS-DA model is defined by the kappa coefficient and the total accuracy calculated from the model's confusion matrix [50].

The discriminant analysis has been used in soil analysis to classify soil attributes according to the different land uses for each site. The PLS-DA model was performed on the laboratory, field, and image datasets and on a combined laboratory and image datasets. The PLS-DA classification was performed with the PLS-Toolbox (Eigenvector, Wenatchee, Washington, USA). The number of latent variables (LVs) was selected based on the recommendation of the PLS-Toolbox optimizing algorithm [50]. The PLS-DA output was used to develop a scoring function in an attempt to evaluate the SQ only by spectral differences. A proportional odds logistic model was used for evaluating the scores of the spectral SQI from the output. The proportional odds model is based on the cumulative probabilities of the coefficient of variation (CV) and the (LV). Consequently, the proposed SSQI is a function of the cumulative probability scoring class, ranging from 0 to 1 as in the SQI:

$$
S S Q I=\left(e^{\left[\beta \times T^{2} \times(C V \times L V)\right]}\right)^{-1}
$$

where $\mathrm{T}^{2}$ refers to the Hotelling's $\mathrm{T}$-squared distribution value [50] that represents a measure of the variation in each sample within the model. The $\mathrm{T}^{2}$ indicates how far each sample is from the center of the model (score $=0$ ) and represents the score distance as an SD within the PLS-DA; $B$ is the slope of the function and is calculated from a range of the minimum and the maximum values of the function. Under a particular CV, only the variables with a high factor loading were retained for the SSQI, and under a particular LV, only the variables with a high factor loading were retained. High factor loading was defined as having an absolute value within $10 \%$ of the highest factor loading [4]. The cumulative variance of the model is the scores for the individual samples, and the coefficients of the LV are the weighting factors obtained from the PLS-DA model. Each LV explains a certain amount of variation in the total dataset; this percentage provides the weight for variables chosen under a given LV. 


\subsubsection{Statistical Analysis}

The soil samples from each treatment (land use) were tested using a one-way analysis of variance (ANOVA) for all soil properties. . The separation of means was subjected to a Tukey Honest Significance Difference (HSD) test. Differences in soil properties were tested for significance at $p \leq 0.05$ between changed land uses and by the results of the F-statistic test. The statistical analysis was performed with STATISTICA Version 11 software (StatSoft, Tulsa, OK, USA).

\section{Results}

\subsection{Soil Properties and Soil Quality}

The mean value of all the soil properties from the Migda site is presented in Table 1, along with their SDs and significance values. The results of the three land uses show significant differences in all soil properties except for P. Significantly higher values of SH and SOM were found in the abandoned agricultural field with no grazing than in the other two land uses. In the agro-pastoral agricultural field, significantly higher values of $\mathrm{HC}, \mathrm{NH}_{4}$, and $\mathrm{K}$ were found than in the other two land uses. Table 2 represents the respective Pearson correlation coefficients $(\mathrm{R})$ for the measured soil properties. The results indicate soil properties with significant correlations $(\mathrm{R} \geq 0.5$, bold numbers) and with highly significant coefficient correlations ( $\mathrm{R}> \pm 0.8$ bold numbers with $(*)$ ). To avoid properties that could be considered as redundant, the multivariate correlation was tested for $\mathrm{R} \geq \pm 0.8$. Later, the soil properties with a high factor loading were eliminated from the SQI. High correlations were found between HC and $\mathrm{SH}$ and $\mathrm{NH}_{4}\left(\mathrm{R}=-0.83\right.$ and $\mathrm{R}=0.79 ; p>0.01$, respectively) and between $\mathrm{SH}$ and $\mathrm{NO}_{3}$, and $\mathrm{K}(\mathrm{R}=-0.92$ and $\mathrm{R}=-0.88 ; p>0.01$, respectively). In addition, a high correlation was found between $\mathrm{K}$ and $\mathrm{NH}_{4}(\mathrm{R}=0.88 ; p=0.01)$.

The results of the soil properties from the Schäfertal site are shown in Table 3. The three land uses show significant differences in all soil properties except for P. Significantly higher values of SH, SOM, PAC and $\mathrm{NH}_{4}{ }^{+}$were found in the forest than in the agricultural land uses. In the agricultural land uses, significantly higher values of $\mathrm{pH}, \mathrm{EC}, \mathrm{NO}_{3}$ and $\mathrm{K}$ were found than in the forest. Significant differences were found between the two agricultural fields in $\mathrm{AWC}, \mathrm{SH}$, and $\mathrm{pH}$. The higher $\mathrm{pH}$ value in the fertilized agricultural field than in the unfertilized field might be explained by the urea application several days before the campaign [69]. In addition, significant differences in soil texture were observed between the three land uses. The soil in the forest had higher clay content, which is related to the ability to retain nutrients (higher cation exchange capacity) and to bind more organic matter. Table 4 represents the Pearson correlations. High negative correlations were found between SOM and $\mathrm{pH}$ and $\mathrm{NO}_{3}(\mathrm{R}=-0.92 ; \mathrm{R}=-0.79, p=0.01$, respectively). In addition, a positive correlation was found between $\mathrm{EC}$ and $\mathrm{NO}_{3}(\mathrm{R}=0.85 ; p=0.01)$. 
Table 1. Soil quality properties for the Migda site, Israel, with the following treatments: (A) abandoned field no grazing; (B) agro-pastoral grazing; and (C) abandoned field with grazing. Statistics include: average value, standard deviation (SD), and indication of significant differences between treatments represented with small letters (a, b, c).

\begin{tabular}{cccc}
\hline Soil Properties & Abandoned Field No Grazing & Agro-Pastoral Grazing & Abandoned Field with Grazing \\
\hline Sand $(\%)(0.063-2.0)$ & $49.12 \pm 1.34^{\mathrm{a}}$ & $44.32 \pm 1.14^{\mathrm{b}}$ & $39.52 \pm 4.15^{\mathrm{c}}$ \\
Silt $(\%)(0.002-0.063)$ & $37.08 \pm 1.09^{\mathrm{a}}$ & $38.68 \pm 1.95^{\mathrm{a}}$ & $38.08 \pm 3.11^{\mathrm{a}}$ \\
Clay $(\%)(<0.002)$ & $13.8 \pm 0.44^{\mathrm{c}}$ & $17.0 \pm 1.01^{\mathrm{b}}$ & $22.4 \pm 2.88^{\mathrm{a}}$ \\
$\mathrm{AWC}(\%)$ & $0.126 \pm 0.03^{\mathrm{a}}$ & $0.120 \pm 0.01^{\mathrm{a}}$ & $0.102 \pm 0.02^{\mathrm{b}}$ \\
$\mathrm{HC}(\mathrm{mm} / \mathrm{h})$ & $0.39 \pm 0.08^{\mathrm{b}}$ & $0.59 \pm 0.106^{\mathrm{a}}$ & $0.288 \pm 0.05^{\mathrm{c}}$ \\
$\mathrm{SH}(\mathrm{psi})$ & $316.16 \pm 5.18^{\mathrm{a}}$ & $159.05 \pm 12.08^{\mathrm{c}}$ & $299.65 \pm 8.43^{\mathrm{b}}$ \\
$\mathrm{SOM}(\%)$ & $4.85 \pm 0.509^{\mathrm{a}}$ & $3.477 \pm 0.306^{\mathrm{b}}$ & $2.814 \pm 0.49^{\mathrm{c}}$ \\
$\mathrm{PAC}$ & $860.49 \pm 159.9^{\mathrm{a}}$ & $889.74 \pm 116.65^{\mathrm{a}}$ & $724.24 \pm 185.07^{\mathrm{b}}$ \\
$\mathrm{pH}$ & $7.39 \pm 0.05^{\mathrm{a}}$ & $7.32 \pm 0.054^{\mathrm{a}}$ & $7.59 \pm 0.058^{\mathrm{b}}$ \\
$\mathrm{EC}(\mu \mathrm{S} / \mathrm{cm})$ & $0.527 \pm 0.09^{\mathrm{a}}$ & $0.535 \pm 0.042^{\mathrm{a}}$ & $0.363 \pm 0.06^{\mathrm{b}}$ \\
$\mathrm{N}-\mathrm{NH}_{4}{ }^{+}(\mathrm{mg} / 100 \mathrm{gr})$ & $3.30 \pm 1.01^{\mathrm{b}}$ & $15.895 \pm 2.63^{\mathrm{a}}$ & $4.76 \pm 1.17^{\mathrm{b}}$ \\
$\mathrm{N}-\mathrm{NO}_{3}(\mathrm{mg} / 100 \mathrm{gr})$ & $12.21 \pm 2.45^{\mathrm{a}}$ & $11.68 \pm 1.28^{\mathrm{a}}$ & $10.29 \pm 1.63^{\mathrm{b}}$ \\
$\mathrm{K}(\mathrm{ml} / 100 \mathrm{gr})$ & $12.78 \pm 3.45^{\mathrm{b}}$ & $31.15 \pm 8.08^{\mathrm{a}}$ & $10.74 \pm 1.32^{\mathrm{b}}$ \\
$\mathrm{P}(\mathrm{mg} / 100 \mathrm{gr})$ & $22.76 \pm 9.25^{\mathrm{a}}$ & $25.155 \pm 11.34^{\mathrm{a}}$ & $18.89 \pm 7.02^{\mathrm{a}}$ \\
\hline
\end{tabular}

Note: AWC: available water content; SH: surface hardness (penetration); HC: hydraulic conductivity (infiltration), PAC: potential active carbon; SOM: soil organic matter; EC: electric conductivity; $\mathrm{NH}_{4}$ : ammonium; $\mathrm{NO}_{3}$ : nitrate; P: phosphorus; $\mathrm{K}$ : potassium; small letters indicate significant differences between treatments. Values in each column followed by the same letter do not differ significantly at $p<\alpha$ using an ANOVA Tukey test. ${ }^{\mathrm{a}}$ high values; ${ }^{\mathrm{b}}$ medium values; ${ }^{\mathrm{c}}$ low values.

Table 2. Pearson correlation coefficients for the measured soil quality properties in the Migda site, Israel. Bold numbers indicate significant differences with $p \leq 0.05$ and bold numbers with (*) indicate highly significant differences with $\mathrm{R} \geq 0.8$ and $p \leq 0.01$.

\begin{tabular}{|c|c|c|c|c|c|c|c|c|c|c|c|}
\hline & $\begin{array}{r}\text { AWC } \\
(\%) \\
\end{array}$ & $\begin{array}{c}\mathbf{H C} \\
(\mathrm{mm} / \mathbf{h}) \\
\end{array}$ & $\begin{array}{l}\text { SH } \\
(\mathbf{p s i})\end{array}$ & $\begin{array}{c}\text { SOM } \\
(\text { Orgs \%) }\end{array}$ & $\begin{array}{l}\text { PAC } \\
\text { (ppm) }\end{array}$ & $\mathbf{p H}$ & $\mathrm{EC}(\mu \mathrm{S} / \mathrm{cm})$ & $\begin{array}{l}\mathbf{N}\left(\mathbf{N H}_{4}\right) \\
(\mathbf{m g} / \mathbf{k g}) \\
\end{array}$ & $\begin{array}{l}\mathrm{N}\left(\mathrm{NO}_{3}\right) \\
(\mathrm{mi} / \mathrm{kg}) \\
\end{array}$ & $\begin{array}{c}\mathbf{K} \\
(\mathrm{mg} / \mathrm{kg}) \\
\end{array}$ & $\begin{array}{c}P \\
(\mathrm{mg} / \mathrm{kg}) \\
\end{array}$ \\
\hline AWC (\%) & 1.00 & & & & & & & & & & \\
\hline $\mathrm{HC}(\mathrm{mm} / \mathrm{h})$ & 0.23 & 1.00 & & & & & & & & & \\
\hline SH (psi) & -0.28 & $-0.83^{*}$ & 1.00 & & & & & & & & \\
\hline SOM (Orgs \%) & 0.54 & 0.20 & -0.08 & 1.00 & & & & & & & \\
\hline PAC (ppm) & 0.28 & 0.41 & -0.34 & 0.37 & 1.00 & & & & & & \\
\hline $\mathrm{pH}$ & -0.36 & -0.49 & 0.55 & -0.44 & -0.40 & 1.00 & & & & & \\
\hline $\mathrm{EC}(\mu \mathrm{S} / \mathrm{cm})$ & 0.31 & 0.67 & -0.50 & 0.55 & 0.45 & -0.62 & 1.00 & & & & \\
\hline $\mathrm{N}\left(\mathrm{NH}_{4}\right)(\mathrm{mg} / \mathrm{kg})$ & 0.20 & 0.79 & $-0.92 *$ & -0.08 & 0.36 & -0.46 & 0.48 & 1.00 & & & \\
\hline $\mathrm{N}\left(\mathrm{NO}_{3}\right)(\mathrm{mi} / \mathrm{kg})$ & 0.14 & 0.35 & -0.22 & 0.42 & 0.40 & -0.48 & 0.58 & 0.24 & 1.00 & & \\
\hline $\mathrm{K}(\mathrm{mg} / \mathrm{kg})$ & 0.20 & 0.74 & $-0.88 *$ & 0.08 & 0.32 & -0.51 & 0.54 & $0.88^{*}$ & 0.31 & 1.00 & \\
\hline $\mathrm{P}(\mathrm{mg} / \mathrm{kg})$ & 0.18 & 0.45 & -0.26 & 0.26 & 0.25 & -0.23 & 0.68 & 0.41 & 0.42 & 0.35 & 1.00 \\
\hline
\end{tabular}

Note: AWC: available water content; SH: surface hardness (penetration); HC: hydraulic conductivity (infiltration); SOM: soil organic matter; PAC: potential active carbon; EC: electrical conductivity; $\mathrm{NH}_{4}$ : ammonium; $\mathrm{NH}_{3}$ : nitrate, $\mathrm{K}$ : potassium; and P: phosphorus. 
Table 3. Soil quality properties for the Schäfertal site, Germany, with the following treatments: (A) agriculture 1; (B) agriculture 2; and (C) forest. Statistics include: average value, standard deviation, and indication of significant differences between treatments.

\begin{tabular}{cccc}
\hline Soil Properties & Fertilized Agricultural Field & Unfertilized Agricultural Field & Forest \\
\hline Sand $(\%)(0.063-2.0)$ & $19.35 \pm 3.87^{\mathrm{b}}$ & $24.07 \pm 3.32^{\mathrm{a}}$ & $24.76 \pm 3.33^{\mathrm{a}}$ \\
Silt $(\%)(0.002-0.063)$ & $61.32 \pm 3.56^{\mathrm{a}}$ & $57.31 \pm 2.23^{\mathrm{b}}$ & $50.5 \pm 2.01^{\mathrm{c}}$ \\
$\mathrm{Clay}(\%)(<0.002)$ & $19.318 \pm 2.74^{\mathrm{b}}$ & $18.62 \pm 1.98^{\mathrm{b}}$ & $24.76 \pm 1.77^{\mathrm{a}}$ \\
$\mathrm{AWC}(\mathrm{m} / \mathrm{m})$ & $0.146 \pm 0.012^{\mathrm{a}}$ & $0.122 \pm 0.019^{\mathrm{b}}$ & $0.104 \pm 0.027^{\mathrm{b}}$ \\
$\mathrm{SH}(\mathrm{psi})$ & $169.32 \pm 18.67^{\mathrm{c}}$ & $260.65 \pm 11.02^{\mathrm{b}}$ & $302.11 \pm 14.90^{\mathrm{a}}$ \\
$\mathrm{SOM}(\%)$ & $3.44 \pm 0.59^{\mathrm{b}}$ & $3.64 \pm 0.51^{\mathrm{b}}$ & $15.96 \pm 4.49^{\mathrm{a}}$ \\
$\mathrm{PAC}(\mathrm{ppm})$ & $961.75 \pm 325.9^{\mathrm{b}}$ & $1048.8 \pm 103.11^{\mathrm{b}}$ & $1651.2 \pm 142.39^{\mathrm{a}}$ \\
$\mathrm{pH}$ & $5.76 \pm 0.34^{\mathrm{a}}$ & $5.26 \pm 0.26^{\mathrm{b}}$ & $3.72 \pm 0.13^{\mathrm{c}}$ \\
$\mathrm{EC}(\mu \mathrm{S} / \mathrm{cm})$ & $159.09 \pm 26.07^{\mathrm{a}}$ & $168.1 \pm 22.88^{\mathrm{a}}$ & $117 \pm 28.266^{\mathrm{b}}$ \\
$\mathrm{N}-\mathrm{NH} 4^{+}(\mathrm{mg} / 100 \mathrm{gr})$ & $<0.03^{\mathrm{c}}$ & $0.1 \pm 0.036^{\mathrm{b}}$ & $1.54 \pm 1.173^{\mathrm{a}}$ \\
$\mathrm{N}-\mathrm{NO} \mathrm{F}_{3}(\mathrm{mg} / 100 \mathrm{gr})$ & $5.05 \pm 0.91^{\mathrm{a}}$ & $5.4 \pm 1.14^{\mathrm{a}}$ & $1.54 \pm 1.17^{\mathrm{b}}$ \\
$\mathrm{K}(\mathrm{ml} / 100 \mathrm{gr})$ & $17.83 \pm 7.26^{\mathrm{a}}$ & $15.26 \pm 5.54^{\mathrm{a}}$ & $6.28 \pm 3.09^{\mathrm{b}}$ \\
$\mathrm{P}(\mathrm{mg} / 100 \mathrm{gr})$ & $2.28 \pm 0.96^{\mathrm{a}}$ & $2.61 \pm 0.97^{\mathrm{a}}$ & $4.12 \pm 1.901^{\mathrm{a}}$ \\
\hline
\end{tabular}

Note: AWC: available water content; SH: surface hardness (penetration); PAC: potential active carbon; SOM: soil organic matter; EC: electric conductivity; $\mathrm{NH}_{4}$ : ammonium; $\mathrm{NO}_{3}$ : nitrate; P: phosphorus; $\mathrm{K}$ : potassium; small superscript letters indicate significant differences between treatments. Values in each column followed by the same letter do not differ significantly at $p<\alpha$ using an ANOVA Tukey test. ${ }^{a}$ high values; ${ }^{\mathrm{b}}$ medium values $;{ }^{\mathrm{c}}$ low values.

Table 4. Pearson correlation coefficients for the measured soil quality properties in the Schäfertal site, Germany. Bold numbers indicate significant differences with $p \leq 0.05$ and bold numbers with $(*)$ indicate highly significant differences with $\mathrm{R} \geq 0.8$ and $p \leq 0.01$.

\begin{tabular}{|c|c|c|c|c|c|c|c|c|c|c|}
\hline & AWC & $\begin{array}{l}\text { SH } \\
(\mathbf{p s i}) \\
\end{array}$ & $\begin{array}{c}\text { SOM } \\
(\%) \\
\end{array}$ & $\begin{array}{c}\text { PAC } \\
\text { n g/kg }\end{array}$ & $\begin{array}{c}\mathrm{NH}_{4}-\mathrm{N} \\
(\mathrm{mg} / 100 \mathrm{~g})\end{array}$ & $\begin{array}{c}\mathrm{NO}_{3}-\mathrm{N} \\
(\mathrm{mg} / \mathbf{1 0 0 g})\end{array}$ & pH & $\begin{array}{c}\text { EC } \\
(\mu \mathrm{S} / \mathrm{cm}) \\
\end{array}$ & $\begin{array}{c}\mathrm{K} \\
(\mathrm{mg} / \mathbf{1 0 0 g}) \\
\end{array}$ & $\begin{array}{c}\mathrm{P} \\
(\mathrm{mg} / \mathbf{1 0 0 g}) \\
\end{array}$ \\
\hline AWC & 1.0 & & & & & & & & & \\
\hline SH (psi) & -0.72 & 1.0 & & & & & & & & \\
\hline $\operatorname{SOM}(\%)$ & -0.49 & 0.64 & 1.0 & & & & & & & \\
\hline PAC n (mg/kg) & -0.57 & 0.62 & 0.77 & 1.0 & & & & & & \\
\hline $\mathrm{NH}_{4}{ }^{+}-\mathrm{N}(\mathbf{m g} / \mathbf{k g})$ & -0.28 & 0.45 & 0.76 & 0.51 & 1.0 & & & & & \\
\hline $\mathrm{NO}_{3}^{-}-\mathrm{N}(\mathbf{m g} / \mathbf{k g})$ & 0.34 & -0.48 & -0.79 & -0.59 & -0.66 & 1.0 & & & & \\
\hline pH & 0.62 & -0.76 & $-0.92 *$ & -0.65 & -0.65 & 0.68 & 1.0 & & & \\
\hline $\mathbf{E C}(\mu \mathrm{S} / \mathbf{c m})$ & 0.31 & -0.34 & -0.55 & -0.49 & -0.54 & $0.85^{*}$ & 0.44 & 1.0 & & \\
\hline K (mg/100g) & 0.19 & -0.44 & -0.56 & -0.34 & -0.33 & 0.68 & 0.61 & 0.53 & 1.0 & \\
\hline$P(\mathrm{mg} / \mathbf{1 0 0 g})$ & -0.21 & 0.39 & 0.49 & 0.618 & 0.05 & -0.11 & -0.45 & 0.07 & -0.12 & 1.0 \\
\hline
\end{tabular}

Note: AWC: available water content; SH: surface hardness (penetration); SOM: soil organic matter; PAC: potential active carbon; $\mathrm{EC}$ : electrical conductivity; $\mathrm{NH}_{4}$ : ammonium; $\mathrm{NO}_{3}$ : nitrate, $\mathrm{K}$ : potassium; and P: phosphorus.

The SQI was developed from the results of the transformed scoring of the soil properties from the two sites. Three PCs that explained $76.71 \%$ of the variance of the original data were chosen for an analysis of data redundancy from the Migda site. The PCA indicated three components with eigenvalues $\geq 1$ (Table 5) that were selected, and the cut-off was placed at the third component. The 
loading values of the first PC1 (38.35\% of variance) indicated $\mathrm{HC}, \mathrm{SH}, \mathrm{pH}, \mathrm{EC}$, and $\mathrm{NH}_{4}$, and had values within $10 \%$ of the highest value. The $\mathrm{SH}$ and $\mathrm{HC}$ were significantly correlated; therefore, they were associated with the highest loading value, and HC was selected for PC1 (38.35\% of variation). For PC2 (28.13\% of variation), the loading values were AWC and SOM. They were not significantly correlated, and both were selected for the SQI. For PC3 (10.23\% of variation), PAC and $\mathrm{NO}_{3}$ were within $10 \%$ of the highest loading value. The total SQI values for the Migda agricultural site were, for the abandoned agricultural field with no grazing, a score of SQI $=0.48$, for the agro-pastoral field, $\mathrm{SQI}=0.61$, and for the abandoned agricultural field with grazing, $\mathrm{SQI}=0.35$, with significant differences between all treatments $(\mathrm{F}=137.5 ; p>0.01)$.

Table 5. Results of the principal component analysis (PCA) of soil properties in the Migda site, Israel. Bold and underlined values indicate underlined factors corresponding to the indicators included in the indices.

\begin{tabular}{cccc}
\hline & Scores PC1 & Scores PC2 & Scores PC3 \\
\hline Eigenvalue & 1.92 & 1.4 & 1.0 \\
Variance & 38.35 & 28.13 & 10.23 \\
Cumulative Variance & 38.35 & 66.48 & 76.71 \\
AWC (\%) & -1.13 & $\underline{\mathbf{2 . 1 2}}$ & -1.06 \\
HC(mm/h) & $\underline{\mathbf{6 . 6 6}}$ & 1.72 & 0.67 \\
SH(psi) & $\mathbf{- 5 . 1 2}$ & 3.37 & -1.33 \\
$\mathrm{SOM}(\mathrm{Orgs} \%$ hcl $)$ & -0.61 & $\underline{\mathbf{5 . 5 9}}$ & -0.10 \\
$\mathrm{PAC}(\mathrm{ppm})$ & -1.88 & -1.14 & $\underline{\mathbf{3 . 7 5}}$ \\
$\mathrm{pH}$ & $\underline{\mathbf{4 . 8 8}}$ & 3.03 & 1.20 \\
$\mathrm{EC}$ & $\underline{\mathbf{5 . 6 0}}$ & 4.30 & -0.99 \\
$\mathrm{~N}\left(\mathrm{NH}_{4}\right)(\mathrm{mg} / \mathrm{kg})$ & $\underline{\mathbf{4 . 9 3}}$ & 3.58 & -1.25 \\
$\mathrm{~N}\left(\mathrm{NO}_{3}\right)(\mathrm{mi} / \mathrm{kg})$ & -1.45 & -2.92 & $\underline{\mathbf{3 . 8 3}}$ \\
\hline
\end{tabular}

Note: AWC: available water content; SH: surface hardness (penetration); HC: hydraulic conductivity (infiltration); SOM: soil organic matter; PAC: potential active carbon; EC: electrical conductivity; $\mathrm{NH}_{4}$ : ammonium; $\mathrm{NH}_{3}$ : nitrate, $\mathrm{K}$ : potassium; and $\mathrm{P}$ : phosphorus.

For the Schäfertal site, the PCA indicated four components with eigenvalues $\geq 1$ (Table 6 ); thus the cut-off was placed at the fourth component. Four PCs that explained $81.95 \%$ of the variance of the original data were chosen for an analysis of data redundancy. The loading values of the first PC (38.9\% of variance) indicated $\mathrm{AWC}, \mathrm{SH}, \mathrm{SOM}, \mathrm{PAC}$, and $\mathrm{NH}_{4}$, and had values within $10 \%$ of the highest value. They were not significantly correlated, and all were selected for the SQI. For the PC2 (20.38\% of variation), the loading values were $\mathrm{EC}$ and $\mathrm{NO}_{3}(\mathrm{R}=0.85)$, which were correlated and associated with the highest loading value; therefore, the EC was selected for the SQI. For the PC3 (13.01\% of variation), $\mathrm{K}$ and for the PC4 (9.66\% of variation), $\mathrm{pH}$ were within $10 \%$ of the highest loading value. The total SQI values for the Schäfertal site were, for the fertilized agricultural field, a score of SQI $=0.51$, for the unfertilized agricultural field, $\mathrm{SQI}=0.39$, and for the forest, $\mathrm{SQI}=0.49$, with significantly higher SQI in the fertilized agricultural field and the forest than in the unfertilized agricultural field $(\mathrm{F}=13.1 ; p>0.01)$. Figures 4 and 5 present the results of the SQI scores in the Migda site and in the Schäfertal site, respectively: (A) the SQI scores and (B) the scores of the physical, biological, and chemical components. In Figure 4A, the Migda site, significant SQI 
differences were found between all agricultural fields $(\mathrm{F}=137.5 ; p>0.01)$. In Figure 5A, the Schäfertal site, no significant SQI differences were found between the fertilized agricultural field and the forest; however, significant differences in the SQI were found in the fertilized agricultural field and the forest compared to the unfertilized agricultural field. Figures $4 \mathrm{~B}$ and 5B show the results of the SQI representing significant differences between the physical, biological, and chemical soil components.

Table 6. Results of the principal component (PC) analysis of soil properties in the Schäfertal site, Germany. Bold and underlined values indicate underlined factors corresponding to the indicators included in the indices.

\begin{tabular}{ccccc}
\hline & Scores PC 1 & Score PC 2 & Scores PC 3 & Scores PC 4 \\
\hline Eigenvalue & 10.01 & 5.3 & 3.3 & 1.2 \\
Variance & 38.9 & 20.38 & 13.01 & 9.66 \\
Cumulative Variance & 38.9 & 59.28 & 72.28 & 81.95 \\
$\mathrm{AWC}(\%)$ & $\underline{\mathbf{4 . 3 0}}$ & -2.34 & -0.66 & 2.12 \\
$\mathrm{SH}(\mathrm{psi})$ & $\underline{\mathbf{4 . 6 0}}$ & -3.24 & -0.38 & 0.11 \\
$\mathrm{SOM}(\%)$ & $\underline{\mathbf{3 . 9 0}}$ & -2.02 & -1.06 & -1.01 \\
$\mathrm{PAC}(\mathrm{ppm})$ & $\underline{\mathbf{- 3 . 2 3}}$ & -1.26 & 1.12 & 0.58 \\
$\mathrm{pH}$ & -0.34 & 0.17 & -0.83 & $\underline{\mathbf{- 1 . 3 0}}$ \\
$\mathrm{EC}(\mathrm{dS} / \mathrm{m})$ & 1.55 & $\underline{\mathbf{3 . 6 5}}$ & -3.58 & -1.06 \\
$\mathrm{~N}(\mathrm{NH})(\mathrm{mg} / \mathrm{kg})$ & $\underline{\mathbf{2 . 7 3}}$ & -1.48 & -1.12 & -0.93 \\
$\left.\mathrm{~N}(\mathrm{NO})_{3}\right)(\mathrm{mg} / \mathrm{kg})$ & 2.75 & $\mathbf{2 . 9 4}$ & 2.22 & -0.11 \\
$\mathrm{~K}(\mathrm{mg} / \mathrm{kg})$ & 2.19 & 1.08 & $\underline{\mathbf{2 . 2 4}}$ & -1.62 \\
\hline
\end{tabular}

Note: AWC: available water content; SH: surface hardness (penetration); SOM: soil organic matter; PAC: potential active carbon; $\mathrm{EC}$ : electrical conductivity; $\mathrm{NH}_{4}$ : ammonium; $\mathrm{NO}_{3}$ : nitrate, $\mathrm{K}$ : potassium; and P: phosphorus.
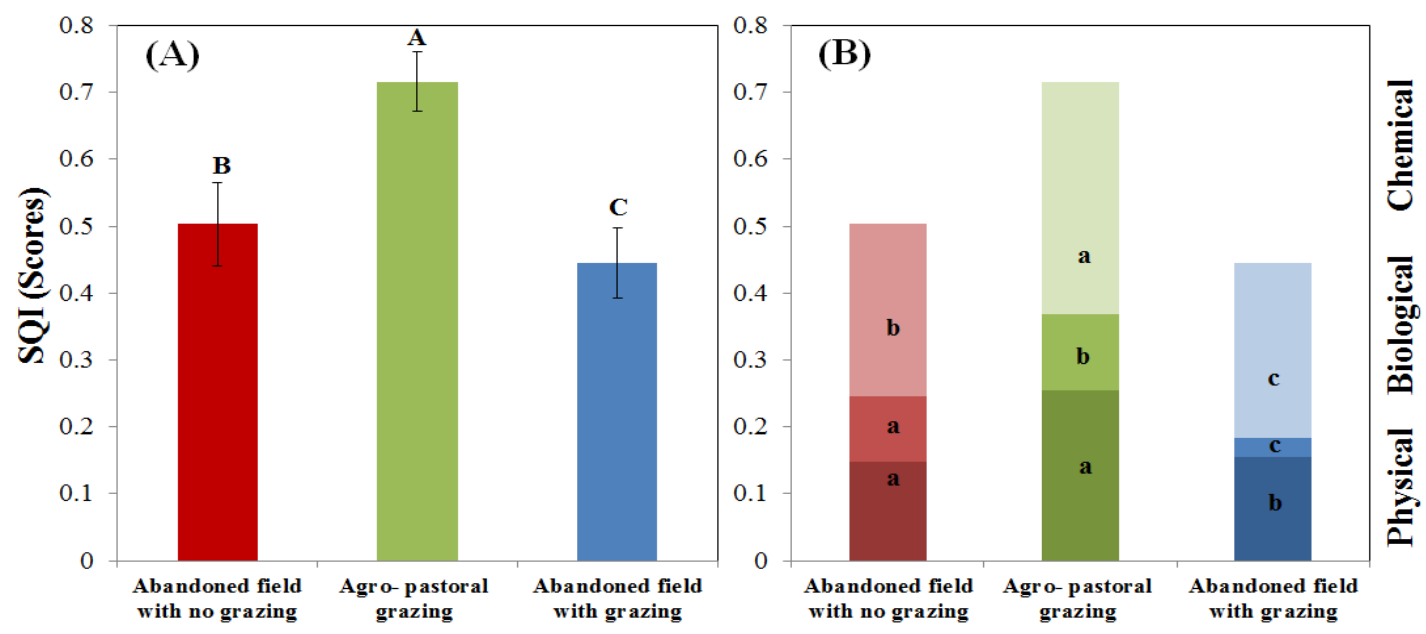

Figure 4. (A) Scores of soil quality indices (SQIs) for the three land uses in the Migda site, Israel: abandoned field with no grazing (red color), agro-pastoral grazing (green color), and abandoned field with grazing (blue color); and (B) the SQI that was calculated by physical, biological, and chemical analyses. Capital letters above the error bars represent significant differences between land uses. Small letters within the columns represent significant differences between soil components. 


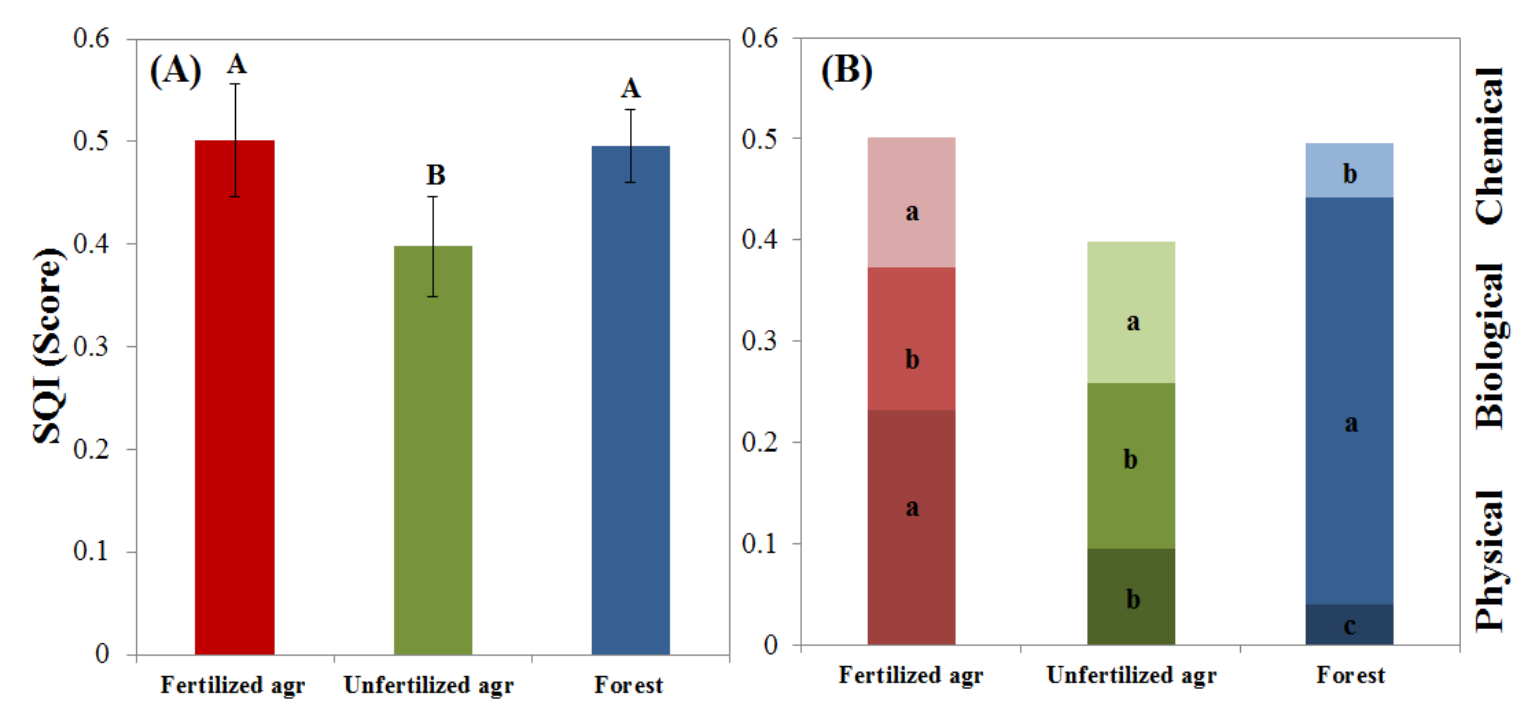

Figure 5. (A) Scores of soil quality indices (SQIs) for the three land uses in the Schäfertal site, Germany: Fertilize agriculture field (red color), unfertilized agriculture field (green color), and forest (blue color); and (B) the SQI that was calculated by physical, biological, and chemical analyses. Capital letters above the error bars represent significant differences between land uses. Small letters within the columns represent significant differences between soil components.

\subsection{Spectral Correlation of Soil Quality Properties}

Table 7 presents the results of the PLS-R analysis including the number of latent variables, the coefficient of determination $\left(\mathrm{R}^{2}\right)$, the RPD, and the VIP projection. The resultant spectral data that explain a good prediction for the two sites are marked in bold in Table 7 and in Figure 6 and 7. The excellent and good results ("excellent" with RPD $\geq 2.5$ and $\mathrm{R}^{2} \geq 0.80$; "good" with RPD between 2-2.5 and $\mathrm{R}^{2} \geq 0.70$ ) of the PLS-R model prediction in the Migda site include clay, sand and silt content, $\mathrm{SH}, \mathrm{pH}, \mathrm{NH}_{4}$, and $\mathrm{NO}_{3}$. In the Schäfertal site, clay content, $\mathrm{SH}, \mathrm{SOM}, \mathrm{pH}, \mathrm{EC}$, and $\mathrm{K}$ showed good results. In addition, the VIP was computed to reveal the score for each wavelength with excellent and good results. The sensitivity bands that were identified by the VIP for the different soil properties and SQI values are presented in Table 7. These bands are in agreement with those that were previously found in other studies [14,31,70]. Figures 6 and 7 shows scatterplots of correlations between soil spectroscopy and laboratory-measured soil values, for the Migda site and Schäfertal site, respectively. The soil properties for the calibration dataset with a coefficient of determination range between 0.67 and 0.95 . Figures 6 and 7 represents the results by RMSC, RMSCV, $\mathrm{R}^{2}$ and the number of LVs for each soil property as an example. The results of the calculated SQI versus spectral measurements in the two study sites, along with their RPDs, are presented in Figure 8. The coefficients of determination in the Migda site were $\mathrm{R}^{2}=0.84$ and $\mathrm{RPD}=2.43$, and in the Schäfertal site, they were $\mathrm{R}^{2}=0.78$ and $\mathrm{RPD}=2.10$, both with good prediction accuracy (Figure 8). 
Table 7. Results of the partial least squares-regression (PLS-R) analysis in terms of spectral regions that are indicative for the soil properties in the two study systems: (1) Migda site, Israel, and (2) Schäfertal site, Germany. Statistics include the number of latent variables ( $\mathrm{LVs}$ ) selected in the PLS-R model, correlation of determination $\left(\mathrm{R}^{2}\right)$, and the ratio of performance to deviation (RPD). Bold numbers refer to the prediction models that were categorized as "excellent" with $\mathrm{RPD} \geq 2.5$ and $\mathrm{R}^{2} \geq 0.80$, and "good" prediction models with RPD between $2-2.5$ and $\mathrm{R}^{2} \geq 0.70$. VIP is the variable importance in projection that presents that wavelength (in nanometers) of selected soil properties with excellent and good prediction results.

\begin{tabular}{|c|c|c|c|c|c|c|c|c|}
\hline \multirow{2}{*}{ Soil properties } & \multicolumn{4}{|c|}{ Migda Site, Israel } & \multicolumn{4}{|c|}{ Schäfertal Site, Germany } \\
\hline & LVs & $\mathbf{R}^{2}$ & RPD & VIP & LVs & $\mathbf{R}^{2}$ & RPD & VIP \\
\hline Sand $(\%)$ & 3 & 0.78 & 2.19 & & 5 & 0.671 & 1.88 & \\
\hline Silt $(\%)$ & 5 & 0.815 & 2.43 & $1900 ; 2220 ; 2205$ & 2 & 0.728 & 1.81 & $1910 ; 2200 ; 2300$ \\
\hline Clay $(\%)$ & 3 & 0.827 & 1.81 & & 4 & 0.877 & 2.83 & \\
\hline $\operatorname{AWC}(\mathbf{m} / \mathbf{m})$ & 4 & 0.471 & 2.18 & & 4 & 0.739 & 1.72 & \\
\hline SH (psi) & 5 & 0.802 & 2.24 & $1850 ; 1900 ; 2140 ; 2200-2350$ & 2 & 0.77 & 2.03 & $1900 ; 2020$ \\
\hline PAC & 4 & 0.677 & 1.84 & & 6 & 0.715 & 1.96 & \\
\hline $\operatorname{SOM}(\%)$ & 3 & 0.611 & 1.75 & & 2 & 0.951 & 4.16 & $1110 ; 1170 ; 1400 ; 1520 ; 1900 ; 2100 ; 2200$ \\
\hline $\mathbf{p H}$ & 2 & 0.85 & 3.07 & $517,747,1000 ; 1400 ; 1930 ; 2220$ & 3 & 0.93 & 2.65 & $657,740,1000 ; 1400 ; 1800 ; 1900 ; 2200$ \\
\hline $\mathbf{E C}(\mu \mathrm{S} / \mathbf{c m})$ & 2 & 0.696 & 2.00 & & 3 & 0.809 & 2.38 & $570,845,990,1100 ; 1410 ; 1850 ; 1920$ \\
\hline $\mathrm{N}-\mathrm{NH}_{4}{ }^{+}(\mathrm{mg} / \mathbf{1 0 0 g r})$ & 4 & 0.795 & 2.34 & $590,870,1850 ; 2052 ; 2040$ & 2 & 0.267 & 1.69 & \\
\hline $\mathrm{N}-\mathrm{NO}_{3}$ (mg/100gr) & 2 & 0.821 & 1.94 & 560,$1770 ; 1850 ; 2050$ & 3 & 0.741 & 1.76 & \\
\hline $\mathrm{K}(\mathbf{m l} \mathbf{l} \mathbf{1 0 0 g r})$ & 5 & 0.614 & 2.00 & & 2 & 0.718 & 2.25 & 535,$1500 ; 1850 ; 1910 ; 2020 ; 2070 ; 2250$ \\
\hline$P(\mathbf{m g} / 100 g r)$ & 2 & 0.74 & 1.92 & & 4 & 0.21 & 0.53 & \\
\hline SQI (overall) & 3 & 0.843 & 2.43 & $\begin{array}{c}570,1200,1780 ; 1850 \\
1900 ; 2100 ; 2050-2350\end{array}$ & 2 & 0.782 & 2.10 & $\begin{array}{c}560,1100 ; 1400 ; 1600-1750 ; 1850 ; 1900 ; \\
2070-2300\end{array}$ \\
\hline
\end{tabular}

Note: AWC: available water content; SH: surface hardness (penetration); PAC: potential active carbon; SOM: soil organic matter; EC: electrical conductivity; $\mathrm{NH}_{4}$ : ammonium; $\mathrm{NH}_{3}$ : nitrate, $\mathrm{K}$ : potassium; and P: phosphorus.

\subsection{Spectral Soil Quality Index (SSQI)}

Table 8 shows the total accuracy and the kappa coefficient values of the field and laboratory models, and the prediction model of the whole image in the two sites. The proportional odds in the PLS-DA classification of the spectral samples are presented in Figures 9 and 10 for the Migda and the Schäfertal sites, respectively. The results of the classification of the laboratory spectral data had a total accuracy of 1 and a kappa coefficient of 1 in the two sites. The same results were achieved after resampling the data to the AISA sensors (moving from 2000 to either 448 or 366 spectral bands). The results of the classification of the field spectral data had a total accuracy of 0.96 and 0.88 , and a kappa coefficient of 0.93 and 0.88 in the Migda and Schäfertal sites, respectively. The results of the classification of the pixels that were extracted from the image showed the same results as the field spectral data, in the two sites. The results of the classification of the combined model (image and laboratory) had a total accuracy of 0.96 and 0.88 , and a kappa coefficient of 0.94 and 0.82 , in the Migda and Schäfertal sites, respectively. The results of the combined model (image and laboratory) 
improved the total accuracy. The PLS-DA provides an explicitly quantitative approach to predict the cumulative probability of soil spectral samples that belong to different soil conditions. The results show the ability to classify land uses according to soil function and the effect on the classification accuracy. As expected, moving from laboratory spectroscopy to field spectroscopy and further to IS reduces the classification accuracy.

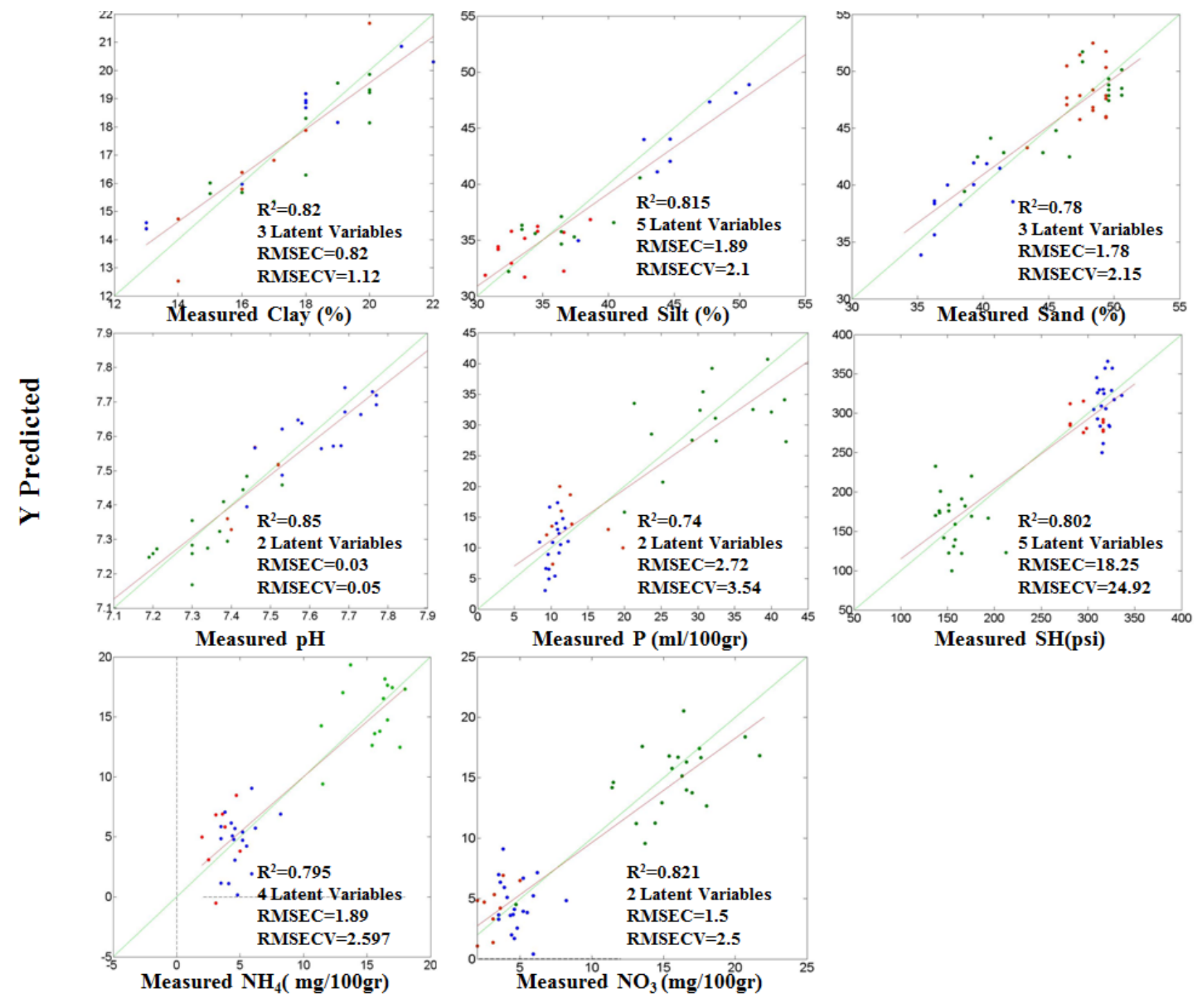

Figure 6. Scatterplots of cross-validation (CV) predicted values versus measured values for several soil properties for the calibration dataset for all land uses in the Migda site, Israel. Calibration models were developed with a partial least squares-regression (PLS-R). RMSEC: root mean square error of calibration; RMSECV: root mean square error of cross-validation; $\mathrm{P}$ : phosphorus $\mathrm{p}$; $\mathrm{NH}_{4}$ : ammonium; $\mathrm{NH}_{3}$ : nitrate, $\mathrm{SH}$ : surface hardness. The colors of the spots represent land-use types: abandoned field with grazing (blue), abandoned field with no grazing (red), agro-pastoral grazing (green). 

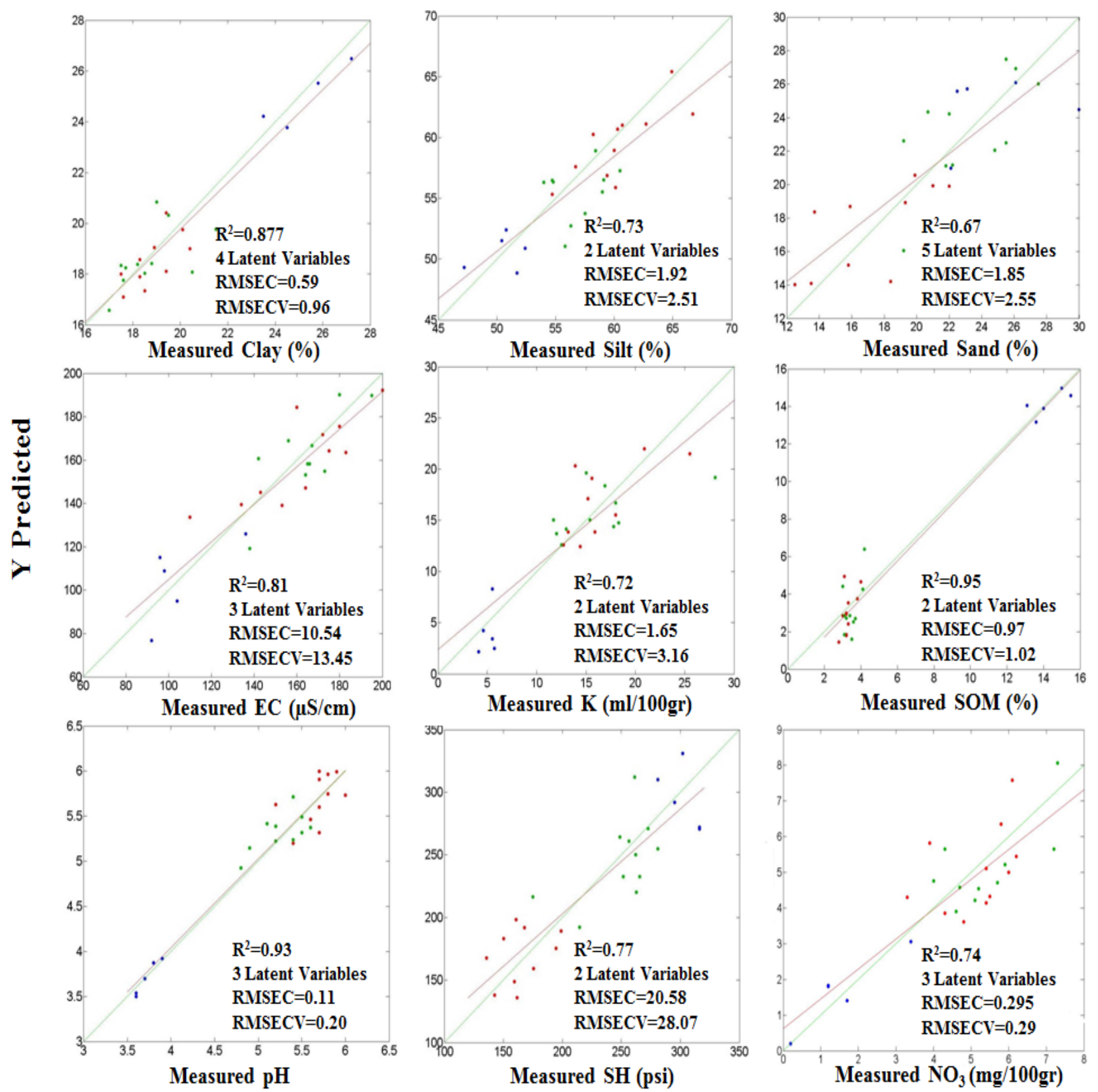

Figure 7. Scatterplots of cross-validation (CV) predicted values versus measured values for several soil properties for the calibration dataset for all land uses in the Schäfertal site, Germany. Calibration models were developed with a partial least squares-regression (PLS-R). RMSEC: root mean square error of calibration; RMSECV: root mean square error of cross-validation; EC: electric conductivity; $\mathrm{K}$ : potassium; $\mathrm{NO}_{3}$ : nitrate; $\mathrm{SOM}$ : soil organic matter; SH: surface hardness. The colors of the spots represent land-use types: forest (blue), fertilized agricultural field (red), unfertilized agricultural field (green). 
(A) Migda site, Israel

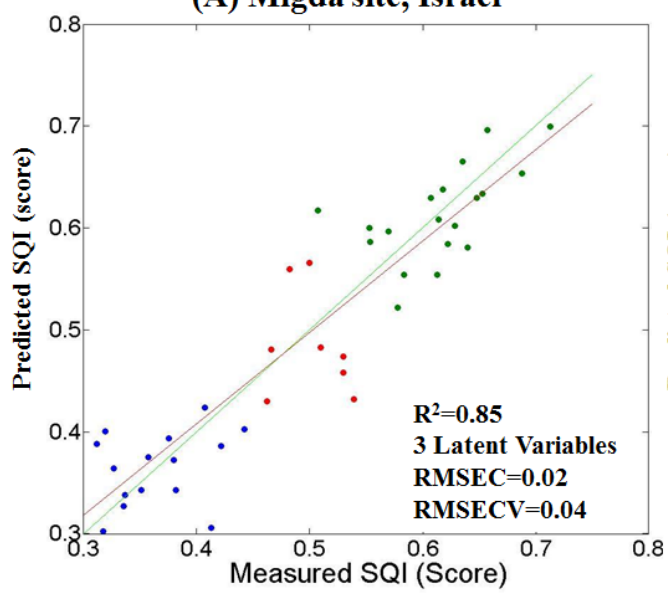

Abandoned field with no grazing Agro-pastoral grazing

Abandoned field with grazing
(B) Schäfertal site, Germany

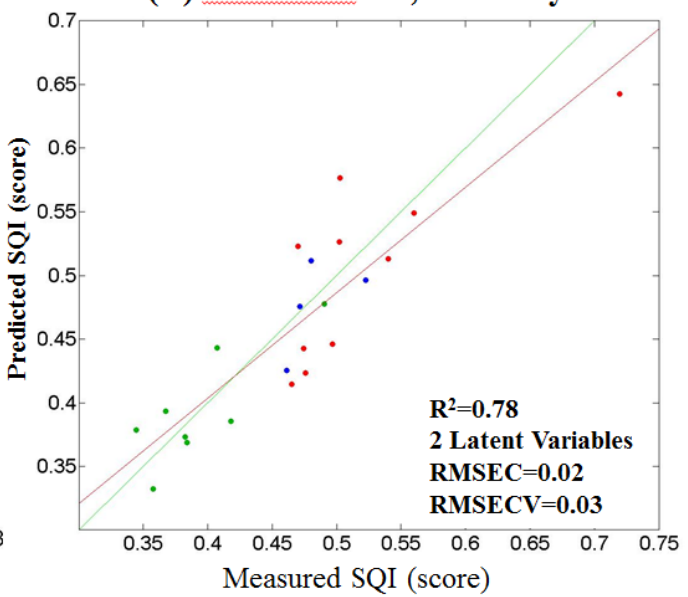

Fertilized agricultural field Unfertilized agricultural field Forest

Figure 8. Scatterplot correlation of soil quality indices (SQI) and reflectance spectroscopy values from the laboratory dataset for the changed land uses: (A) the Migda site, Israel; and (B) the Schäfertal site, Germany. Calibration models were developed with a partial least squares-regression (PLS-R). RMSEC: root mean square error of calibration; RMSECV: root mean square error of cross-validation.
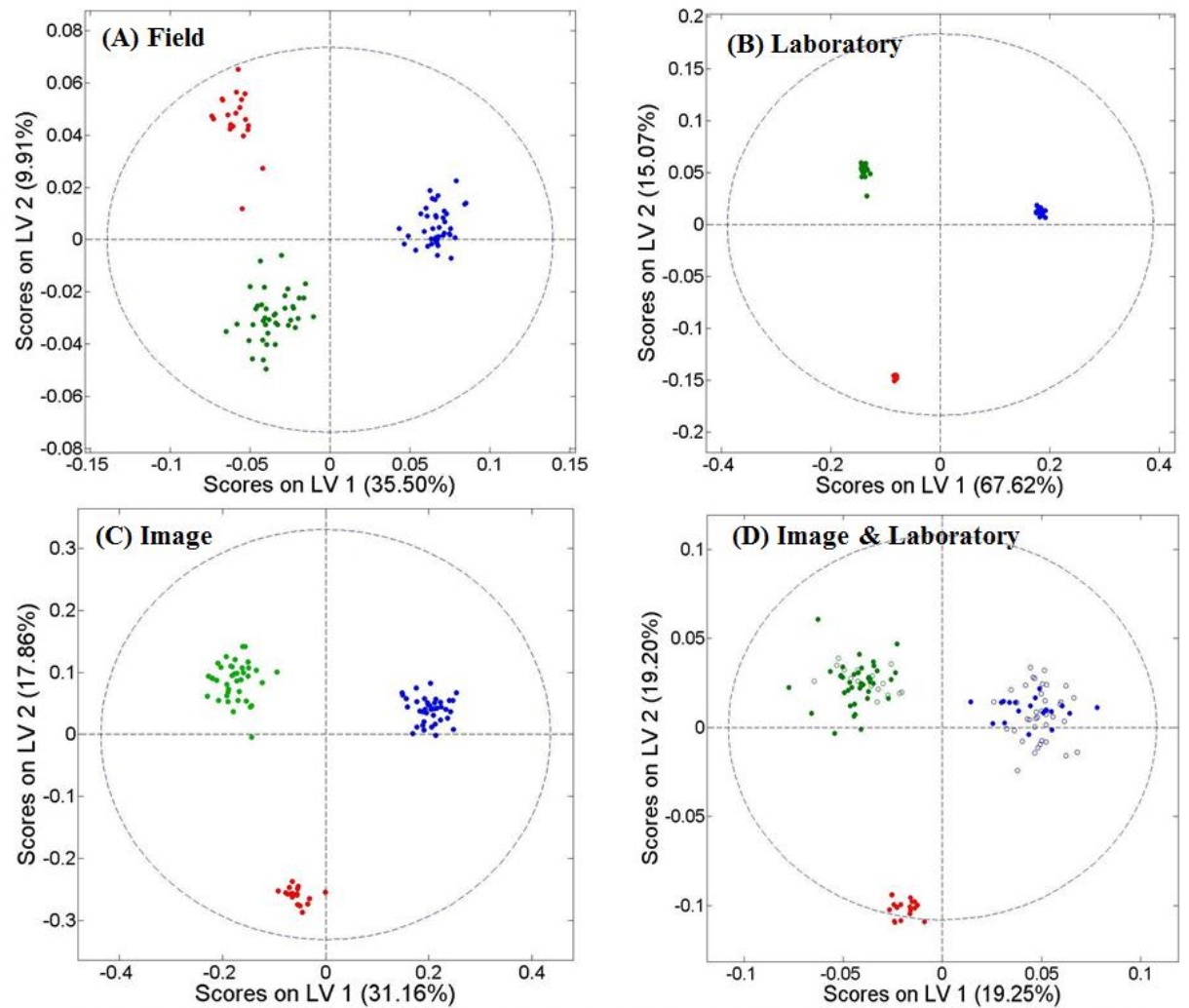

Abandoned field with no grazing Abandoned field with grazing Agro-pastoral grazing

Figure 9. Partial least squares-discriminant analysis (PLS-DA) classification of the different land uses in the Migda site, Israel, using data of: (A) field spectroscopy; (B) laboratory spectroscopy; (C) airborne imaging spectroscopy; and (D) merged image and laboratory spectroscopy. Dashed circles indicate the 95\% confidence level. 

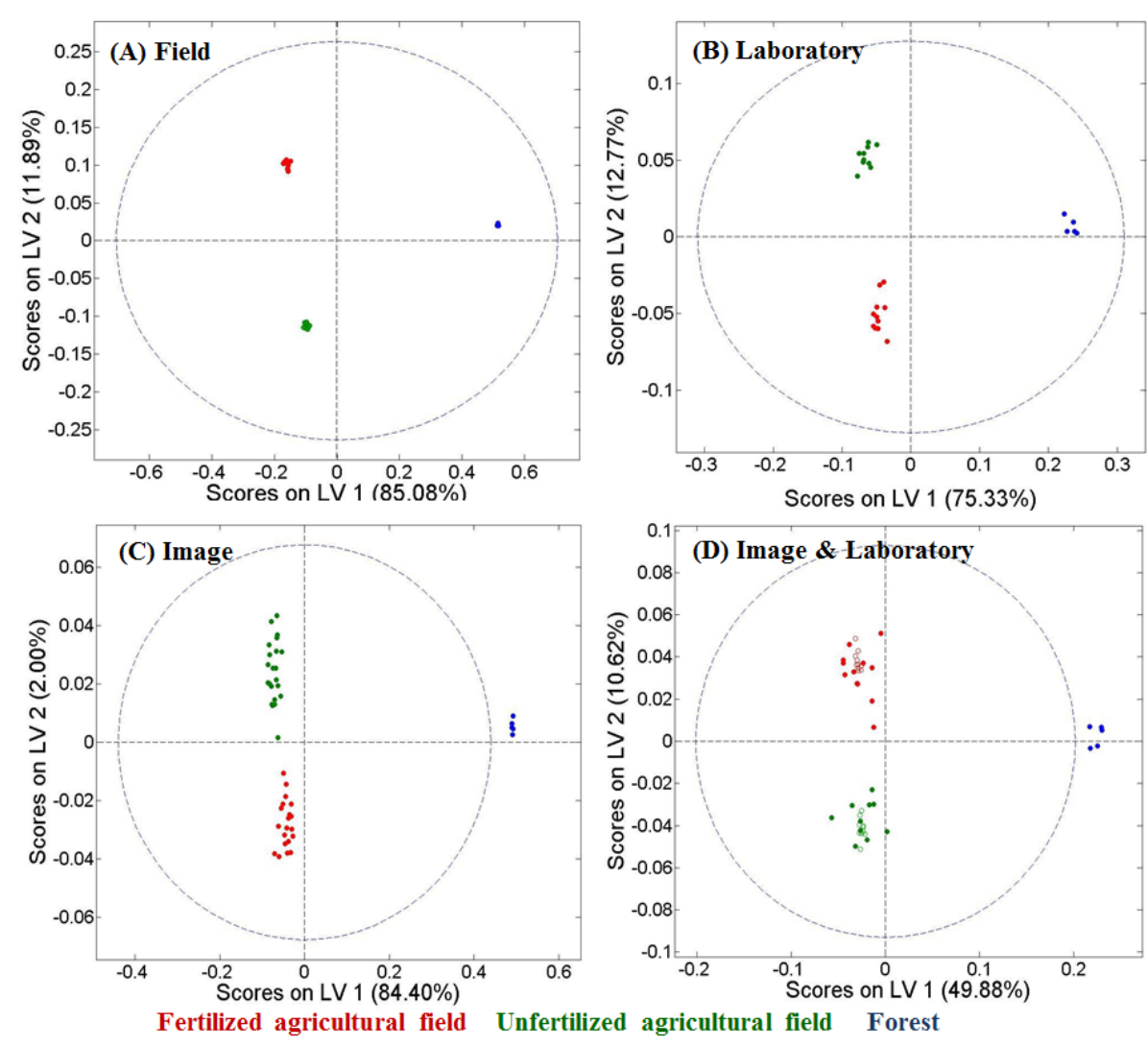

Figure 10. Partial least squares-discriminant analysis (PLS-DA) classification of the different land uses in the Schäfertal site, Germany, using data of: (A) field spectroscopy; (B) laboratory spectroscopy; (C) airborne imaging spectroscopy; and (D) merged image and laboratory spectroscopy. Dashed circles indicate the $95 \%$ confidence level.

Table 8. The results of the classification total accuracy and the kappa coefficient of PLS-DA models as derived for the different land uses of the soil spectral sampling, for the Migda, Israel and Schäfertal, Germany sites.

\begin{tabular}{cccc}
\hline Study Site & Spectral Sampling & $\begin{array}{c}\text { PLS-DA } \\
\text { (Total Accuracy) }\end{array}$ & $\begin{array}{c}\text { PLS-DA } \\
\text { (Kappa Coefficient) }\end{array}$ \\
\hline \multirow{5}{*}{ Migda, Israel } & Laboratory (2000 bands) & 1 & 1 \\
& Resampled laboratory (448 bands) & 1 & 1 \\
& Field (448 bands) & 0.96 & 0.93 \\
& Image (358 bands) & 0.96 & 0.94 \\
& Image and laboratory (358 bands) & 0.97 & 0.95 \\
& Image prediction (358 bands) & 0.92 & 0.91 \\
\hline Schäfertal, Germany & Laboratory (2000 bands) & 1 & 1 \\
& Resampled laboratory (366 bands) & 1 & 0.80 \\
& Field (366 bands) & 0.88 & 0.82 \\
& Image (300 bands) & 0.88 & 0.85 \\
& Image and laboratory (300 bands) & 0.90 & 0.80 \\
\hline
\end{tabular}


The classifications of the soil condition scores in the two systems were well separated, and each sample represents SSQI scores. The SSQI algorithm was implemented on the output results of the PLS-DA combined model (laboratory spectral data and the extracted pixels from the image). The predictions of the SSQI model in the two sites are shown in Figures 11 and 12. The classification predictions of the image had a total accuracy of 0.92 and 0.82 , and a kappa coefficient of 0.91 and 0.80, in the Migda and Schäfertal sites, respectively. The SSQI indicates a higher value than the SQI; the model of the SSQI is a proportional model that is not based on the individual probability of each class but on the cumulative probabilities. Therefore, the proportions between classes that explain the changes caused by management are more essential than the actual values. The extracted pixels from the SSQIs predicted from the spectral data were significantly correlated to the SQIs calculated from the laboratory-measured data in the two sites $(\mathrm{F}=9.75, p \geq 0.01 ; \mathrm{F}=13.57, p \geq 0.01$, respectively). The correlations between the SSQI and the SQI were $\mathrm{R}^{2}=0.71$ and $\mathrm{R}^{2}=0.7$, in the Migda and Schäfertal sites, respectively. The spatial selection of the sampling points and the number of sampling affect the strength of the correlation coefficient between the SSQI and SQI.

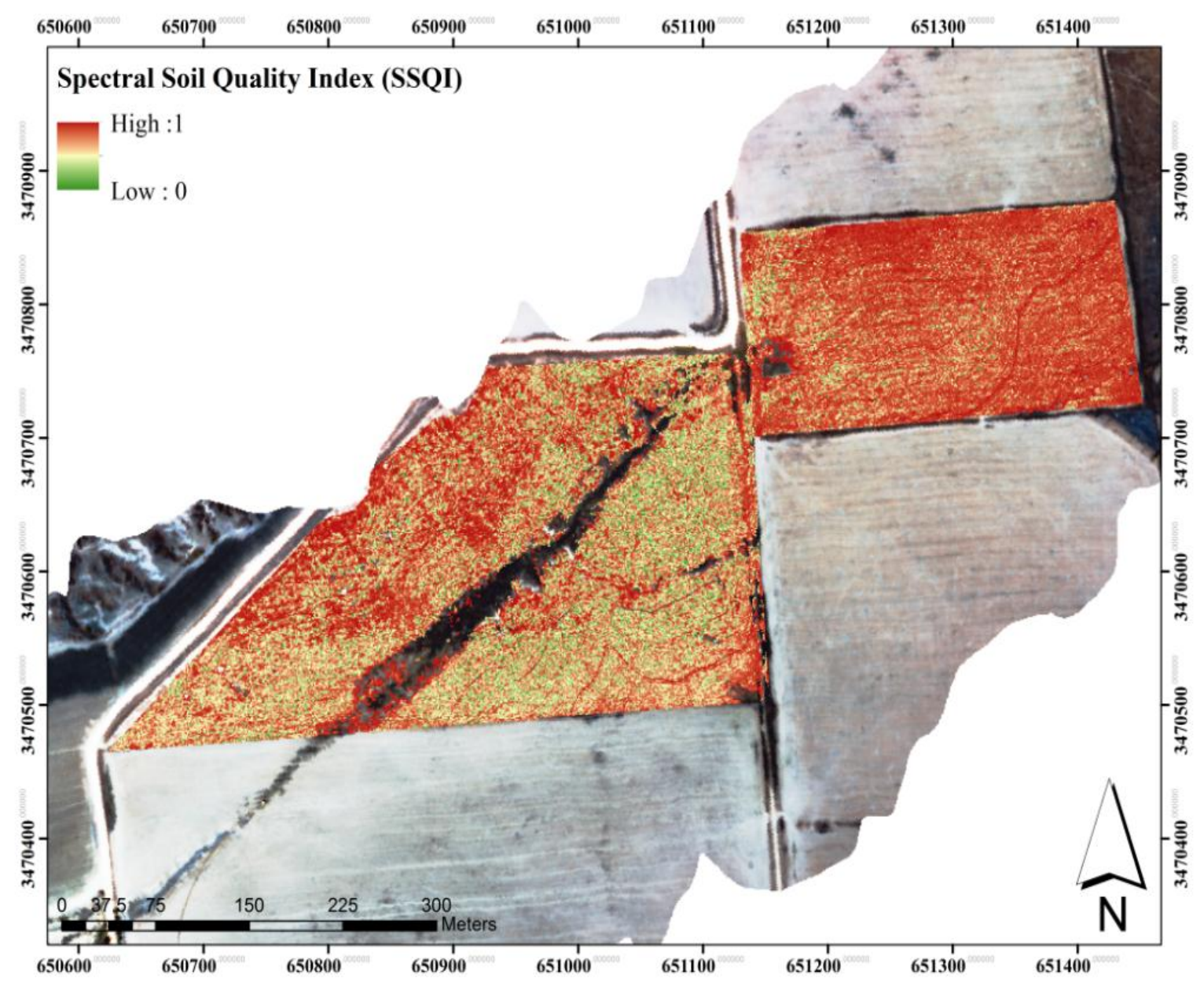

Figure 11. Hyperspectral imaging spectroscopy of the spectral soil quality index (SSQI) at Migda site, Israel. 


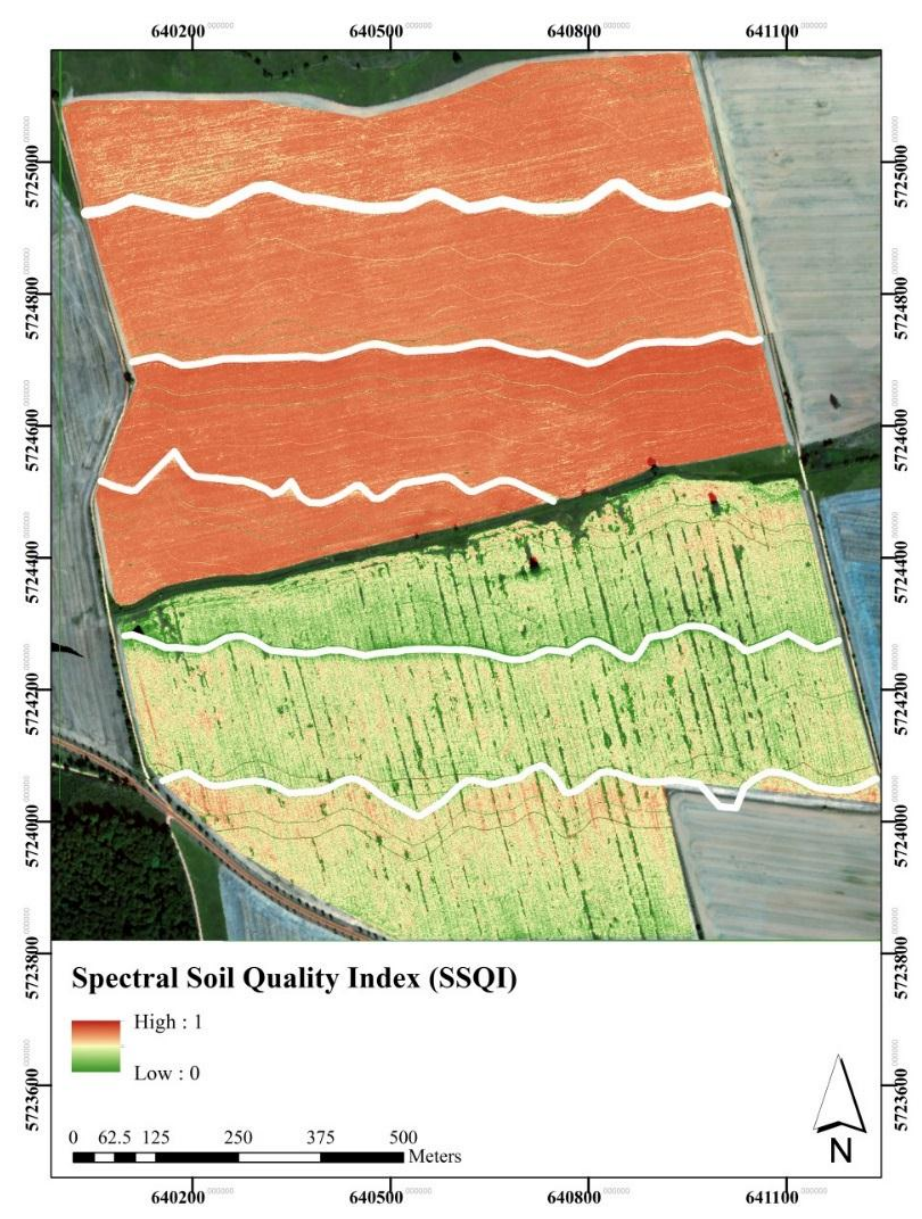

Figure 12. Hyperspectral imaging spectroscopy of the spectral soil quality index (SSQI) at Schäfertal site, Germany.

\section{Discussion}

To the best of our knowledge, at present, most studies dealing with optical remote sensing technologies for SQ assessment focus on several soil properties as indicators of SQ for a specific soil type or land use [10], and much less research exists on the potential of IS for developing SQ surface maps. These studies mainly use point spectroscopy, either in the laboratory or in the field, and do not implement IS on a regional scale. In the move from point spectroscopy to IS, the transition is not only from micro- to macroscales, but a whole new set of challenges is encountered. In the current study, the prediction of SQIs was explored in the context of two different experimental agricultural sites under different climatic regimes using spectroscopic techniques and IS. It was found that the SSQIs from IS were not significantly different from traditional SQIs. The correlations between the extracted pixels from SSQI map and the SQI that were measured in the field were $\mathrm{R}^{2}=0.71$ and $\mathrm{R}^{2}=0.7$, in the Migda and Schäfertal sites, respectively. The analysis of the current study demonstrated the ability and reliability of SSQI and key soil properties to be efficiently predicted by VIS-NIR-SWIR spectroscopy.

\subsection{Soil Properties and the Soil Quality Index}

Many soil properties can be measured, depending on the expected soil function, land use, and management system, for assessing SQ. However, the process of measuring and analyzing a large number 
of soil properties is usually time-consuming and costly. In this study, the Cornell Soil Health Test (CSHT) protocols were adopted for analyzing 13 physical, biological, and chemical soil properties. Selecting indicators (soil properties) that are sensitive enough to detect the effects of management systems on SQ is essential. For example, in our study, soil texture was excluded from the analysis because it is a fixed soil property and cannot be readily influenced by management practices [4,30,71]. We focused here on the effect of management on the SQ and soil properties. However, developing soil texture maps is of great importance as this property determines the water retention of the soil and can serve as an input for hydrological models and simulations [72]. In addition, conventional methods for selecting proper indicators based on the PCA were used. Data redundancy was effectively reduced by using PCA and by reducing the soil properties with high multivariate correlations that were considered as redundant. Different weights were selected for each soil property according to the PCA results. These results showed that an appropriate number of soil properties can provide information for evaluating land-use impact on SQ in different study sites.

The SQI in the Migda site shows significant differences between all land uses and between their biological and chemical components. The SQI in the Schäfertal site shows no significant differences between the fertilized agricultural field and the forest land use. However, a significant reduction in the SQI value was found in the unfertilized agricultural field and the other two land uses. The differences between the two agricultural fields might be related to the urea fertilizer application on the fertilized agricultural field several days prior to the field campaign. It is known that urea fertilization leads to substantial increases in the $\mathrm{pH}$ value in the first three weeks after application [73]. The fertilized agricultural field showed a significantly higher $\mathrm{pH}$ value than the unfertilized agricultural field. In addition, even if no significant differences in the SQI were found between the fertilized agricultural field and the forest in the Schäfertal site, the physical, biological, and chemical components differed significantly. This fact reflects an important advantage of the SQI model as an integrative approach that recognizes many processes in soils [74]. The SQI equation is valid for establishing the degree of soil degradation as a function of soil properties $[2,75,76]$. In addition, it enables land-use effects on soil properties to be identified and monitored by the proportions between the physical, biological, and chemical components.

\subsection{Predictability of Indicators and Indices}

Overall, the predictions of individual indicators and the SQI were "good" to "excellent" for several soil properties (Table 7). However, in each site, the correlation of the soil properties by spectroscopy was different and could be related to the variety of chromophores, which vary with the environmental conditions and the status of the five soil formation factors (climate, topography, parent material, organic matter, and time), and long-term management. In addition, the accuracy is related to the soil properties' concentrations and proportions, and to the number of sampling points. For example, the correlation of $\mathrm{NO}_{3}$ and $\mathrm{NH}_{4}$ were ranked as "good" to "excellent" in the Migda site, and "poor" to "medium" in the Schäfertal site (Table 7). The concentration of $\mathrm{NO}_{3}$ in the Schäfertal site was too low (>0.03 mg/100 gr) to be identified by conventional laboratory techniques, and therefore, it couldn't be identified by spectroscopic means. Spectroscopy is a reliable tool for assessing soil properties; however, it is site-specific and related to the soil function and structure. Previous studies have shown the ability of spectroscopy to predict several soil properties, such as texture, $\mathrm{SOM}, \mathrm{AWC}, \mathrm{NH}_{4}, \mathrm{NO}_{3}, \mathrm{EC}$, and $\mathrm{pH}$, with different prediction levels $[15,25,31,66]$. These differences are probably associated with the energy 
of the absorbance and reflectance of molecular bonds in the NIR region due to the combination of $\mathrm{C}-\mathrm{H}$, $\mathrm{N}-\mathrm{H}, \mathrm{C}-\mathrm{O}, \mathrm{C}-\mathrm{N}$ and $\mathrm{O}-\mathrm{H}$ groups (chromophores) [77-79], minerals, water, and nutrients.

The spectral reflectance of a specific soil is a consequence of the entire chromophore interaction with the electromagnetic energy. This is related to the spectral curve that can serve as a footprint of the chromophore's overall existence in the examined matter. The ability to predict SQI is not only due to these primary soil properties, but also to a range of secondary properties that improve the prediction ability. The mechanism by which the prediction of these soil properties is possible depends on how well they are correlated with primary soil variables. The predictions of the integrated soil properties and the SQI predictions had "good" prediction accuracy (Figure 8). These results demonstrate that VIS-NIR-SWIR spectroscopy is suitable for the multidimensional evaluation of SQI. The SQIs were significantly correlated, in the Migda site $\left(\mathrm{R}^{2}=0.84 ; p<0.01\right)$ and the Schäfertal site $\left(\mathrm{R}^{2}=0.78\right.$; $p<0.01)$. Furthermore, after finalizing the SQI, the PLS-R technique can be used rapidly, making it possible to analyze a large number of samples in a practical and timely manner as a prediction model. These qualities make spectroscopic analysis, combined with PLS-R, an attractive method for environmental monitoring, especially for modeling SQ in changed land uses [10].

\subsection{Spectral Indices for Soil Quality Assessment}

In both sites, no differences were found between the classification accuracy of the laboratory and the resampled laboratory model (reduction from 2000 to either 448 or 366 bands). The reduction in the spectral bands and the resampling of data to the AISA spectral bands did not affect the classification accuracy [80]. Other studies showed the same trend in which no advantages were found with continuous spectral data [81]. The classification accuracy depends on several factors, such as the spectral variance between classes, the number of classes, the number of sampling points, noise effects, the spectral resolution, and the PPTs. PPTs can improve the classification accuracy by increasing the variability between classes while decreasing the variability within classes. In this study, we used the second-order transformation of the polynomial Savitzky-Golay smoothing, an autoscale transformation, and GLSW. These PPTs were found to be very effective in data transformation, leading to a highly accurate classification. This conclusion is in agreement with a similar soil study [18]. Pre-processing may be relevant for addressing some of the problems associated with IS. In this study, no significant differences were found between the classification accuracy of the field and the extracted pixels from the image model in both sites. This fact can be related to soil aggregation, particle size distribution, water content, and the presence of additional elements in the soil, such as vegetation litter, rock particles, and mineral deposits. However, differences between the classification accuracy of the laboratory and the field model (undisturbed soil sample) were found and can be related to the standardization of the sample preparation and the measurement procedure. The integrated model of extracted pixels from the image and the laboratory improved the classification accuracy (Table 8). In addition, the classification accuracy of the Migda site was higher than that of the Schäfertal site, which can be related to the number of sampling points that reduced the predication accuracy of the model.

IS has drawbacks relative to point spectrometry, such as a low signal-to-noise ratio, atmosphere attenuation, a varying field of view for every pixel, spectral instability, a low integration time for a given pixel, a spectral mixing problem, optical shifts from one pixel to another and more. To upscale the model to IS, additional corrections must be amplified, such as the BRDF effect, and the removal of water 
absorption bands, masking the vegetation signal, and more. In Figure 12, which shows the SSQI surface map of the Schäfertal site, the striping of the BRDF is shown; this is due to the mosaic of the six AISA flight lines that were stitched into one. The BRDF effect reduces the total accuracy of the SSQI model in the Schäfertal site. Because most of the applications for soil were developed for point spectrometry, their immediate adaptation for the IS domain requires proper attention and adequate solutions to minimize the above problems [3,36,82]. The SSQI map (Figure 11) shows spatial pattern of soil quality, in the abandoned agricultural field with grazing. This pattern may be related to the small wadi that crosses the field and may affect the grazing density and distribution. This study provides a framework for assessing SSQI by the VIS-NIR-SWIR spectral range with IS as a preliminary tool for detecting hotspots of soil degradation at a regional scale. The PLS-DA model describes the possible separation of predefined soil conditions. Furthermore, these results demonstrate the sensitivity of reflectance spectroscopy to management changes in converted land-use soil conditions.

\subsection{Monitoring Soil Quality with IS}

IS is a promising tool for studying soil properties in large spatial domains. Most of the studies using IS addressed specific soil properties and not integrative SQ monitoring approaches [3]. IS is a rapid, nondestructive, reproducible, and cost-effective analytical method, and therefore useful for SQ assessment. Although the IS approach is a cost-effective method, it hasn't been fully adopted because it is difficult to process and has not yet been recognized by many end-users [36]. As the IS product is a geo-positioning mosaic comprising many spectral points, traditional (quantitative) approaches that successfully work for point spectrometry measurements may also be suitable for the imaging domain. The benefits of this technique include a reduction of the sampling processing time and an increase in the number of samples that can be analyzed within time and budget constraints, and hence, an improvement of the detection of changes in SQ in a given area. The SSQI is a diagnostic tool for assessing SQ in changed land uses and treatments. The correlations between the SSQI and the SQI were good in both sites. However, there is a need for the additional development of modeling approaches to create links between soil point spectroscopy and IS at a large spatial scale., Examining the cause of the soil degradation requires an extensive assessment of SQ by soil measurements and the use of models such as the SQI (using the physical, biological, and chemical components). Note that the use of IS as presented in this study can be relevant only in area with bare soil. In this study, the forests in Schäfertal site and abandoned agricultural fields in Migda site were excluded from the analysis since they were covered with vegetation.

SQ policies usually address specific management goals, such as productivity, waste recycling, and environmental protection [60]. Thus, methodologies for SQ assessment should be able to measure the specific soil functions and the soil ecosystem services associated with these management goals. The ability of spectral analysis for evaluating SQ in point spectroscopy and IS will allow field implementation with IS and portable spectrometer equipment as new ways for monitoring and mapping SQ in order to address soil threats in a near real-time manner [10]. This is an important implication for sustainable agricultural management, in particular, and land use, in general, because greater spatial and temporal resolution sampling will be possible at a lower cost. The SSQI maps can be used in various ways. Firstly, they may help in segmenting the landscape into soil-landscape units for each soil composition according to the land-use dynamics. Secondly, IS data can be analyzed using physically and chemically based methods to derive soil properties and soil function. Moreover, IS can be used as a data 
source supporting digital soil mapping [9]. Finally, IS methods can facilitate the mapping of inaccessible areas by reducing the need for extensive time-consuming and costly field surveys in the future $[9,83]$.

\section{Conclusions}

The current study underscores the potential application of reflectance spectroscopy and IS as reliable diagnostic screening tools for assessing SQ at a local scale, as well as the many soil attributes that are used to compute the SQI. The results demonstrate that: (1) correlations between the predicted spectral values and the calculated SQI were $\mathrm{R}^{2}=0.84 ; \mathrm{RPD}=2.43$ and $\mathrm{R}^{2}=0.78 ; \mathrm{RPD}=2.10$ in the Israeli and the German study sites, respectively; (2) the key soil properties of SQ can be predicted with "good" or "moderate" accuracy, but these are site-specific and related to the environmental conditions and the status of the five soil formation factors, as well as to long-term management; (3) the SQI for both agricultural experimental sites were predicted with "good" accuracy and were as good as those calculated from laboratory-measured data; (4) the utilized linear parametric models, PCA, PLS-R, and PLS-DA, improved the ability to predict soil properties and SQI, and they enabled us to overcome the problems of multivariant and highly collinear data such as that gained by spectroscopy; (5) the classification of soils using the PLS-DA statistical model into spectrally defined entities provides a basis for spatially explicit and quantitative definitions for developing the SSQI at a regional scale; and (6) the SSQI score related to land-use management could be differentiated by reflectance data, thus demonstrating that the SSQI is related to the productive function of the soil. The VIS-NIR-SWIR spectroscopy and IS can be used as a reproducible method for monitoring the effects of land use and for identifying hotspots of soil degradation at a regional scale. IS can provide a reliable approach for assessing SSQI and can be used for a rapid, low-cost analysis of soil conditions at appropriate scales under different management, land-use, and soil types. Thus, SSQI maps may help in evaluating the effects of management practices and in developing a better understanding of soil functions in the near future.

\section{Acknowledgments}

Financial support from the Transnational Access to Research Infrastructures Activity in the 7th Framework Program of the EC under the ExpeER project (REA grant agreement no. 262060) for conducting the research is gratefully acknowledged. The research at the German site was supported by TERENO (TERrestrial ENvironmental Observatories, www.tereno.net).

\section{Author Contributions}

Tarin Paz-Kagan initiated and performed the experiments, produced the results, and wrote the first draft of the manuscript. Christoph Salbach, Andreas Schmidt, Angela Lausch, and Steffen Zacharias participated in producing the results from the Schäfertal site in Germany. Eli Zaady, Gila Notesco, Eyal Ben-Dor, and Arnon Karnieli participated in producing the results from the Migda site in Israel. All authors reviewed and approved the manuscript.

\section{Conflicts of Interest}

The authors declare no conflict of interest. 


\section{References}

1. Karlen, D.L.; Ditzler, C.A.; Andrews, S.S. Soil quality: Why and how? Geoderma 2003, 114, $145-156$.

2. Lal, R. Restoring soil quality to mitigate soil degradation. Sustainability 2015, 7, 5875.

3. Ben-Dor, E.; Chabrillat, S.; Dematte, J.A.M.; Taylor, G.R.; Hill, J.; Whiting, M.L.; Sommer, S. Using imaging spectroscopy to study soil properties. Remote Sens. Environ. 2009, 113 (Suppl. 1), S38-S55.

4. Andrews, S.S.; Karlen, D.L.; Mitchell, J.P. A comparison of soil quality indexing methods for vegetable production systems in northern california. Agric. Ecosyst. Environ. 2002, 90, 25-45.

5. Gugino, B.K.; Abawi, G.S.; Idowe, O.J.; Schindelbeck, R.R.; Smith, L.L.; Thies, J.E.; Wolfe, D.W.; Van Es, H.M. Cornell Soil Health Assessment Training Manual; New York State Agricultural Experiment Station, Cornell University: New York, NY, USA, 2009.

6. Doran, J.W.; Parkin, T.B. Quantitative indicators of soil quality: A minimum data set. In Methods for Assessing Soil Quality; Doran, J.W., Jones, A.J., Eds.; Soil Science Society of America: Madison, WI, USA, 1996; pp. 25-37.

7. Rezaei, S.A.; Gilkes, R.J.; Andrews, S.S. A minimum data set for assessing soil quality in rangelands. Geoderma 2006, 136, 229-234.

8. Doran, J.W.; Parkin, T.B. Defining and assessing soil quality. In Defining Soil Quality for $a$ Sustainable Environment; Doran, J.W., Coleman, D.C., Bezdicek, D.F., Stewart, B.A., Eds.; Soil Science Society of America, Inc.: Madison, WI, USA, 1994; pp. 3-21.

9. Mulder, V.L.; de Bruin, S.; Schaepman, M.E.; Mayr, T.R. The use of remote sensing in soil and terrain mapping-A review. Geoderma 2011, 162, 1-19.

10. Askari, M.S.; Cui, J.; O’Rourke, S.M.; Holden, N.M. Evaluation of soil structural quality using VIS-NIR spectra. Soil Tillage Res. 2015, 146, 108-117.

11. Ben-Dor, E.; Banin, A. Visible and near-infrared $(0.4 \mathrm{~nm}-1.1 \mathrm{~nm})$ analysis of arid and semiarid soils. Remote Sens. Environ. 1994, 48, 261-274.

12. Conforti, M.; Castrignanò, A.; Robustelli, G.; Scarciglia, F.; Stelluti, M.; Buttafuoco, G. Laboratorybased Vis-NIR spectroscopy and partial least square regression with spatially correlated errors for predicting spatial variation of soil organic matter content. Catena 2015, 124, 60-67.

13. Eisele, A.; Chabrillat, S.; Hecker, C.; Hewson, R.; Lau, I.C.; Rogass, C.; Segl, K.; Cudahy, T.J.; Udelhoven, T.; Hostert, P., et al. Advantages using the thermal infrared (TIR) to detect and quantify semi-arid soil properties. Remote Sens. Environ. 2015, 163, 296-311.

14. Viscarra Rossel, R.A.; Walvoort, D.J.J.; McBratney, A.B.; Janik, L.J.; Skjemstad, J.O. Visible, near infrared, mid infrared or combined diffuse reflectance spectroscopy for simultaneous assessment of various soil properties. Geoderma 2006, 131, 59-75.

15. Gholizadeh, A.; Boruvka, L.; Saberioon, M.; Vasát, R. Visible, near-infrared, and mid-infrared spectroscopy applications for soil assessment with emphasis on soil organic matter content and quality: State-of-the-art and key issues. Appl. Spectrosc. 2013, 67, 1349-1362.

16. Mouazen, A.; Karoui, R.; De Baerdemaeker, J.; Ramon, H. Classification of soil texture classes by using soil visual near infrared spectroscopy and factorial discriminant analysis techniques. J. Near Infrared Spectrosc. 2005, 13, 231-240. 
17. Mouazen, A.M.; Kuang, B.; de Baerdemaeker, J.; Ramon, H. Comparison among principal component, partial least squares and back propagation neural network analyses for accuracy of measurement of selected soil properties with visible and near infrared spectroscopy. Geoderma 2010, 158, 23-31.

18. Rozenstein, O.; Paz-Kagan, T.; Salbach, C.; Karnieli, A. Comparing the effect of preprocessing transformations on methods of land-use classification derived from spectral soil measurements. IEEE J. Sel. Top. Appl. Earth Obs. Remote Sens. 2015, 6, 2393-2404.

19. Shepherd, K.D.; Walsh, M.G. Development of reflectance spectral libraries for characterization of soil properties. Soil Sci. Soc. Am. J. 2002, 66, 988-998.

20. Savitzky, A.; Golay, M.J.E. Smoothing and differentiation of data by simplified least squares procedures. Anal. Chem. 1964, 36, 1627-1639.

21. Fystro, G. The prediction of $\mathrm{c}$ and $\mathrm{n}$ content and their potential mineralisation in heterogeneous soil samples using vis-nir spectroscopy and comparative methods. Plant Soil 2002, 246, 139-149.

22. Martens, H.; Нøy, M.; Wise, B.M.; Bro, R.; Brockhoff, P.B. Pre-whitening of data by covariance-weighted pre-processing. J. Chemom. 2003, 17, 153-165.

23. Kinoshita, R.; Moebius-Clune, B.N.; van Es, H.M.; Hively, W.D.; Bilgilis, A.V. Strategies for soil quality assessment using visible and near-infrared reflectance spectroscopy in a western kenya chronosequence. Soil Sci. Soc. Am. J. 2012, 76, 1779-1788.

24. Awiti, A.O.; Walsh, M.G.; Shepherd, K.D.; Kinyamario, J. Soil condition classification using infrared spectroscopy: A proposition for assessment of soil condition along a tropical forest-cropland chronosequence. Geoderma 2008, 143, 73-84.

25. Cécillon, L.; Barthès, B.G.; Gomez, C.; Ertlen, D.; Genot, V.; Hedde, M.; Stevens, A.; Brun, J.J. Assessment and monitoring of soil quality using near-infrared reflectance spectroscopy (NIRs). Eur. J. Soil Sci. 2009, 60, 770-784.

26. Odlare, M.; Svensson, K.; Pell, M. Near infrared reflectance spectroscopy for assessment of spatial soil variation in an agricultural field. Geoderma 2005, 126, 193-202.

27. Velasquez, E.; Lavelle, P.; Barrios, E.; Joffre, R.; Reversat, F. Evaluating soil quality in tropical agroecosystems of colombia using nirs. Soil Biol. Biochem. 2005, 37, 889-898.

28. McCarty, G.W.; Reeves, J.B.; Reeves, V.B.; Follett, R.F.; Kimble, J.M. Mid-infrared and near-infrared diffuse reflectance spectroscopy for soil carbon measurement. Soil Sci. Soc. Am. J. 2002, 66, 640-646.

29. Cohen, M.J.; Prenger, J.P.; DeBusk, W.F. Visible-near infrared reflectance spectroscopy for rapid, nondestructive assessment of wetland soil quality. J. Environ. Qual. 2005, 34, 1422-1434.

30. Idowu, O.J.; Van Es, H.M.; Abawi, G.S.; Wolfe, D.W.; Ball, J.I.; Gugino, B.K.; Moebius, B.N.; Schindelbeck, R.V.; Bilgili, R.A. Farmer-oriented assessment of soil quality using field, laboratory, and VNIR spectroscopy methods. Plant Soil 2008, 307, 243-253.

31. Paz-Kagan, T.; Shachak, M.; Zaady, E.; Karnieli, A. A spectral soil quality index (SSQI) for characterizing soil function in areas of changed land use. Geoderma 2014, 230-231, 171-184.

32. Ben-Dor, E.; Levin, N.; Saaroni, H. A spectral based recognition of the urban environment using the visible and near-infrared spectral region $(0.4-1.1 \mu \mathrm{m})$. A case study over Tel-Aviv, Israel. Int. J. Remote Sens. 2001, 22, 2193-2218. 
33. Goetz, A.F.H.; Vane, G.; Solomon, J.E.; Rock, B.N. Imaging spectroscopy for earth remote sensing. Science 1985, 228, 1147-1153.

34. Green, R.O.; Eastwood, M.L.; Sarture, C.M.; Chrien, T.G.; Aronsson, M.; Chippendale, B.J.; Faust, J.A.; Pavri, B.E.; Chovit, C.J.; Solis, M., et al. Imaging spectroscopy and the airborne visible/infrared imaging spectrometer (AVIRIS). Remote Sens. Environ. 1998, 65, 227-248.

35. Nocita, M.; Stevens, A.; van Wesemael, B.; Aitkenhead, M.; Bachmann, M.; Barthès, B.; Ben-Dor, E.; Brown, D.J.; Clairotte, M.; Csorba, A. Chapter four-Soil spectroscopy: An alternative to wet chemistry for soil monitoring. In Advances in Agronomy; Donald, L.S., Ed.; Academic Press: San Diego, CA, USA, 2015; Volume 132, pp 139-159.

36. Ben-Dor, E.; Taylor, R.G.; Hill, J.; Demattê, J.A.M.; Whiting, M.L.; Chabrillat, S.; Sommer, S. Imaging spectrometry for soil applications. In Advances in Agronomy; Donald, L.S., Ed.; Academic Press: San Diego, CA, USA, 2008; Volume 97, pp 321-392.

37. Weber, B.; Olehowski, C.; Knerr, T.; Hill, J.; Deutschewitz, K.; Wessels, D.C.J.; Eitel, B.; Büdel, B. A new approach for mapping of biological soil crusts in semidesert areas with hyperspectral imagery. Remote Sens. Environ. 2008, 112, 2187-2201.

38. Sobrino, J.A.; Franch, B.; Mattar, C.; Jiménez-Muñoz, J.C.; Corbari, C. A method to estimate soil moisture from airborne hyperspectral scanner (AHS) and ASTER data: Application to SEN2FLEX and SEN3EXP campaigns. Remote Sens. Environ. 2012, 117, 415-428.

39. Pascucci, S.; Casa, R.; Belviso, C.; Palombo, A.; Pignatti, S.; Castaldi, F. Estimation of soil organic carbon from airborne hyperspectral thermal infrared data: A case study. Eur. J. Soil Sci. 2014, 65, 865-875.

40. Zacharias, S.; Bogena, H.; Samaniego, L.; Mauder, M.; Fuß, R.; Pütz, T.; Frenzel, M.; Schwank, M.; Baessler, C.; Butterbach-Bahl, K.; et al. A network of terrestrial environmental observatories in germany. Vadose Zone J. 2011, 10, 955-973.

41. Paz-Kagan, T.; Shachak, M.; Zaady, E.; Karnieli, A. Evaluation of ecosystem responses to land-use change using soil quality and primary productivity in a semi-arid area, Israel. Agric. Ecosyst. Environ. 2014, 193, 9-24.

42. Pimstein, A.; Eitel, J.U.H.; Long, D.S.; Mufradi, I.; Karnieli, A.; Bonfil, D.J. A spectral index to monitor the head-emergence of wheat in semi-arid conditions. Field Crop. Res. 2009, 111, 218-225.

43. Sanchez, P.A.; Couto, W.; Buol, S.W. The fertility capability soil classification system: Interpretation, applicability and modification. Geoderma 1982, 27, 283-309.

44. Ollesch, G.; Kistner, I.; Meissner, R.; Lindenschmidt, K.-E. Modelling of snowmelt erosion and sediment yield in a small low-mountain catchment in germany. Catena 2006, 68, 161-176.

45. Ollesch, G.; Sukhanovski, Y.; Kistner, I.; Rode, M.; Meissner, R. Characterization and modelling of the spatial heterogeneity of snowmelt erosion. Earth Surf. Process. Landf. 2005, 30, 197-211.

46. Luo, J.; Ying, K.; Bai, J. Savitzky-golay smoothing and differentiation filter for even number data. Signal Process. 2005, 85, 1429-1434.

47. Chang, C.-W.; Laird, D.A.; Mausbach, M.J.; Hurburgh, C.R. Near-infrared reflectance spectroscopy-Principal components regression analyses of soil properties. Soil Sci. Soc. Am. J. 2001, 65, 480-490. 
48. Vågen, T.-G.; Shepherd, K.D.; Walsh, M.G. Sensing landscape level change in soil fertility following deforestation and conversion in the highlands of madagascar using vis-nir spectroscopy. Geoderma 2006, 133, 281-294.

49. Wise, B.M.; Gallagher, N.B.; Martin, E.B. Application of PARAFAC2 to fault detection and diagnosis in semiconductor etch. J. Chemom. 2001, 15, 285-298.

50. Wise, B.; Gallagher, N.; Bro, R.; Shaver, J.; W., W.; Koch, R. Chemometrics Tutorial for PLS_Toolbox and Solo; Eigenvector Research, Inc: Wenatchee, WA, USA, 2006.

51. Brook, A.; Ben-Dor, E. Supervised vicarious calibration (SVC) of multi-source hyperspectral remote-sensing data. Remote Sens. 2015, 7, 6196-6223.

52. Rogaß, C.; Spengler, D.; Bochow, M.; Segl, K.; Lausch, A.; Doktor, D.; Roessner, S.; Behling, R.; Wetzel, H.-U.; Kaufmann, H. Reduction of radiometric miscalibration-Applications to pushbroom sensors. Sensors 2011, 11, 6370-6395.

53. Schläpfer, D.; Richter, R.; Feingersh, T. Operational brdf effects correction for wide-field-of-view optical scanners (brefcor). IEEE Trans. Geosci. Remote Sens. 2015, 53, 1855-1864.

54. Tucker, C.J. Red and photographic infrared linear combinations for monitoring vegetation. Remote Sens. Environ. 1979, 8, 127-150.

55. Karnieli, A.; Tsoar, H. Spectral reflectance of biogenic crust developed on desert dune sand along the Israel-Egypt border. Int. J. Remote Sens. 1995, 16, 369-374.

56. Schindelbeck, R.R.; van Es, H.M.; Abawi, G.S.; Wolfe, D.W.; Whitlow, T.L.; Gugino, B.K.; Idowu, O.J.; Moebius-Clune, B.N. Comprehensive assessment of soil quality for landscape and urban management. Landsc. Urban Plan. 2008, 88, 73-80.

57. Black, C.A. Methods of Soil Analysis: Part I Physical and Mineralogical Properties; American Society of Agronomy: Madison, WI, USA, 1965.

58. Stevenson, F.J. Nitrogen-Organic Forms. In Methods of Soil Analysis, Part 3; Chemical Methods, 4th ed; Soil Science Society of America: Madison, WI, USA, 2005.

59. Ankeny, M.D.; Ahmed, M.; Kaspar, T.C.; Horton, R. Simple field method for determining unsaturated hydraulic conductivity. Soil Sci. Soc. Am. J. 1991, 55, 467-470.

60. Andrews, S.S.; Karlen, D.L.; Cambardella, C.A. The soil management assessment framework. Soil Sci. Soc. Am. J. 2004, 68, 1945-1962.

61. Karlen, D.L.; Andrews, S.S.; Doran, J.W. Soil quality: Current concepts and applications. In Advances in Agronomy; Academic Press: San Diego, CA, USA, 2001; Volume 74, pp 1-40.

62. Govaerts, B.; Sayre, K.D.; Deckers, J. A minimum data set for soil quality assessment of wheat and maize cropping in the highlands of mexico. Soil Till. Res. 2006, 87, 163-174.

63. Masto, R.E.; Chhonkar, P.K.; Purakayastha, T.J.; Patra, A.K.; Singh, D. Soil quality indices for evaluation of long-term land use and soil management practices in semi-arid sub-tropical India. Land Degrad. Dev. 2008, 19, 516-529.

64. Masto, R.E.; Chhonkar, P.K.; Singh, D.; Patra, A.K. Soil quality response to long-term nutrient and crop management on a semi-arid inceptisol. Agric. Ecosyst. Environ. 2007, 118, 130-142.

65. Efron, B.; Gong, G. A leisurely look at the bootstrap, the jackknife, and cross-validation. Am. Stat. 1983, 37, 36-48. 
66. Cécillon, L.; Cassagne, N.; Czarnes, S.; Gros, R.; Brun, J.-J. Variable selection in near infrared spectra for the biological characterization of soil and earthworm casts. Soil Biol. Biochem. 2008, 40, 1975-1979.

67. Wold, S.; Sjöström, M.; Eriksson, L. Pls-regression: A basic tool of chemometrics. Chemom. Intell. Lab. Syst. 2001, 58, 109-130.

68. Singh, K.P.; Malik, A.; Mohan, D.; Sinha, S.; Singh, V.K. Chemometric data analysis of pollutants in wastewater-A case study. Anal. Chim. Acta 2005, 532, 15-25.

69. Fox, R.H.; Hoffman, L.D. The effect of $\mathrm{N}$ fertilizer source on grain yield, $\mathrm{N}$ uptake, soil $\mathrm{pH}$, and lime requirement in no-till corn. Agron. J. 1981, 73, 891-895.

70. Westad, F.; Martens, H. Variable selection in near infrared spectroscopy based on significance testing in partial least squares regression. J. Near Infrared Spectrosc. 2000, 117, 117-124.

71. Carter, M.R. Soil quality for sustainable land management: Organic matter and aggregation interactions that maintain soil functions. Agronomy 2002, 94, 38-47.

72. De Lannoy, G.J.M.; Koster, R.D.; Reichle, R.H.; Mahanama, S.P.P.; Liu, Q. An updated treatment of soil texture and associated hydraulic properties in a global land modeling system. $J . A d v$. Model. Earth Syst. 2014, 6, 957-979.

73. Martikainen, P.J. Nitrification in forest soil of different $\mathrm{pH}$ as affected by urea, ammonium sulphate and potassium sulphate. Soil Biol. Biochem. 1985, 17, 363-367.

74. Bastida, F.; Zsolnay, A.; Hernández, T.; Garcia, C. Past, present and future of soil quality indices: A biological perspective. Geoderma 2008, 147, 159-171.

75. Zhao, Q.; Liu, S.; Deng, L.; Dong, S.; Wang, C. Soil degradation associated with water-level fluctuations in the manwan reservoir, lancang river basin. Catena 2014, 113, 226-235.

76. Šarapatka, B.; Bednář, M. Assessment of potential soil degradation on agricultural land in the czech republic. J. Environ. Qual. 2015, 44, 154-161.

77. Bushong, J.T.; Norman, R.J.; Slaton, N.A. Near-infrared reflectance spectroscopy as a method for determining organic carbon concentrations in soil. Commun. Sci. Plant Anal. 2015, 46, 1791-1801.

78. Fidêncio, P.H.; Poppi, R.J.; de Andrade, J.C. Determination of organic matter in soils using radial basis function networks and near infrared spectroscopy. Anal. Chim. Acta 2002, 453, 125-134.

79. Vasques, G.M.; Grunwald, S.; Sickman, J.O. Comparison of multivariate methods for inferential modeling of soil carbon using visible/near-infrared spectra. Geoderma 2008, 146, 14-25.

80. Ben-Dor, E.; Banin, A. Near infrared analysis (NIRA) as a method to simultaneously evaluate spectral featureless constituents in soils. Soil Sci. 1995, 159, 259-270.

81. Herrmann, I.; Pimstein, A.; Karnieli, A.; Cohen, Y.; Alchanatis, V.; Bonfil, D.J. Lai assessment of wheat and potato crops by ven $\mu$ s and sentinel-2 bands. Remote Sens. Environ. 2011, 115, 2141-2151.

82. Ustin, S.L.; Roberts, D.A.; Gamon, J.A.; Asner, G.P.; Green, R.O. Using imaging spectroscopy to study ecosystem processes and properties. BioScience 2004, 54, 523-534.

83. De Paul Obade, V.; Lal, R. Assessing land cover and soil quality by remote sensing and geographical information systems (GIS). Catena 2013, 104, 77-92.

(C) 2015 by the authors; licensee MDPI, Basel, Switzerland. This article is an open access article distributed under the terms and conditions of the Creative Commons Attribution license (http://creativecommons.org/licenses/by/4.0/). 